


\title{
What do we learn about redistribution effects of pension systems from internationally comparable measures of Social Security Wealth?
}

\author{
Michele Belloni \\ Ca' Foscari University of Venice; Netspar; \\ Cerp-Collegio Carlo Alberto
}

Raluca E. Buia

Ca' Foscari University of Venice

Danilo Cavapozzi

Ca' Foscari University of Venice; Netspar

\author{
Agar Brugiavini \\ Ca' Foscari University of Venice
}

Ludovico Carrino

Ca' Foscari University of Venice; King's College London

Cristina E. Orso

Ca' Foscari University of Venice

\author{
Giacomo Pasini \\ Ca' Foscari University of Venice; Netspar
}

\begin{abstract}
We present novel estimates of Social Security Wealth (SSW) at the individual level based on the SHARE survey. Our estimates are based on a rigorous methodology taking into account country-specific legislations, the earnings history and the longevity prospects of individuals. The key advantage over existing estimates is that our measures of SSW is fully comparable across countries. This allows us to construct several indexes of the redistribution enacted by the pension systems in Europe. Moreover, simple correlations between SSW and alternative measures of private wealth are presented to provide descriptive evidence of the displacement effect of SSW on private wealth.
\end{abstract}

\section{Keywords}

Social Security Wealth, SHARE, redistribution

JEL Codes

D14, D31, H55

Address for correspondence:

\author{
Michele Belloni \\ Department of Economics \\ Ca' Foscari University of Venice \\ Cannaregio 873, Fondamenta S.Giobbe \\ 30121 Venezia - Italy \\ Phone: (++39) 041234915 \\ Fax: $(++39) 0412349176$ \\ e-mail:michele.belloni@unive.it
}

This Working Paper is published under the auspices of the Department of Economics of the Ca' Foscari University of Venice. Opinions expressed herein are those of the authors and not those of the Department. The Working Paper series is designed to divulge preliminary or incomplete work, circulated to favour discussion and comments. Citation of this paper should consider its provisional character.

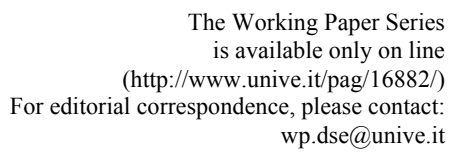

The Working Paper Series wp.dse@unive.it
Department of Economics

Ca' Foscari University of Venice

Cannaregio 873, Fondamenta San Giobbe

30121 Venice Italy

Fax: ++39041 2349210 


\title{
What do we learn about redistribution effects of pension systems from internationally comparable measures of Social Security Wealth? ${ }^{1}$
}

\author{
Michele Belloni $^{\mathrm{a}, \mathrm{b}, \mathrm{c}}$, Agar Brugiavini ${ }^{\mathrm{a}}$, Raluca E. Buia ${ }^{\mathrm{a}}$, Ludovico Carrino ${ }^{\mathrm{a}, \mathrm{d}}$, \\ Danilo Cavapozzi ${ }^{\mathrm{a}, \mathrm{b}}$, Cristina E. Orso ${ }^{\mathrm{a}}$, Giacomo Pasini ${ }^{\mathrm{a}, \mathrm{b}}$ \\ ${ }^{\mathrm{a}}$ Ca' Foscari University of Venice; ${ }^{\mathrm{b}}$ Netspar; \\ ${ }^{\mathrm{c}}$ Cerp-Collegio Carlo Alberto; ${ }^{\mathrm{d}}$ King's College London
}

\begin{abstract}
We present novel estimates of Social Security Wealth (SSW) at the individual level based on the SHARE survey. Our estimates are based on a rigorous methodology taking into account country-specific legislations, the earnings history and the longevity prospects of individuals. The key advantage over existing estimates is that our measures of SSW is fully comparable across countries. This allows us to construct several indexes of the redistribution enacted by the pension systems in Europe. Moreover, simple correlations between SSW and alternative measures of private wealth are presented to provide descriptive evidence of the displacement effect of SSW on private wealth.
\end{abstract}

Keywords: Social Security Wealth, SHARE, redistribution

\footnotetext{
${ }^{1}$ This paper uses data from SHARE Wave 4 (DOI:10.6103/SHARE.w4.600), as well as from the SHARE Job Episodes Panel (DOI 10.6103/SHARE.jep.600). See Börsch-Supan et al. (2013) for methodological details. The SHARE data collection has been primarily funded by the European Commission through FP5 (QLK6-CT-2001-00360), FP6 (SHARE-I3: RII-CT-2006-062193, COMPARE: CIT5-CT-2005-028857, SHARELIFE: CIT4-CT-2006-028812) and FP7 (SHARE-PREP: N²11909, SHARE-LEAP: N²27822, SHARE M4: $\mathrm{N}^{\circ}$ 261982). Additional funding from the German Ministry of Education and Research, the U.S. National Institute on Aging (U01_AG09740-13S2, P01_AG005842, P01_AG08291, P30_AG12815, R21_AG025169, Y1-AG-4553-01, IAG_BSR06-11, OGHA_04-064) and from various national funding sources is gratefully acknowledged (see www.share-project.org). We are grateful to the Italian Ministry of Education, University and Research-MIUR for generous support under the PRIN grant 2010T8XAXB. The authors would also like to thank James Banks, Rob Alessie and the participants to the 2016 VIU Summer Institute on Ageing, Venice International University, Venice.
} 


\section{Introduction}

In most European countries social security is the prevailing form of insurance and assistance to protect the well-being of individuals at older ages ${ }^{2}$. However, the increasing pressure to meet financial sustainability goals has hampered the action of many governments in reaching the desired level of coverage for retirees. The degree of old-age protection guaranteed by the social security system depends on a number of determinants: the institutional set-up and the rules in place, mortality prospects, labour force participation and indexation rules. The interaction of these forces may lead to different patterns of old-age protection outcomes, which make it imperative to have access to a rich dataset where all these features can be measured and compared across countries in order to carry out meaningful comparisons. Old-age pension rules are often quite complex and could vary considerably over time and across countries, for instance in terms of eligibility rules or benefit computation rules. Hence, it is important to rely on a synthetic and flexible measure of the pension provisions that is able to capture all these different characteristics in a parsimonious way.

Redistribution aspects of pension systems are particularly relevant as the well-being of a large number of individuals may largely depend on public provisions during the retirement years. Yet, while there exists a vast literature on redistribution policies implemented through general taxation, much less has been done on the role of social security as a means of transferring resources, either intentionally or unintentionally. In

\footnotetext{
${ }^{2}$ In this paper we use the terms "social security" and "public pensions" as synonymous. The difference between social security and pensions is relevant in those countries where private occupational pensions play a role, such as the Netherlands. However, since we focus our attention on the first pillar only, we can adopt this simplification. For those cases where we want to mark the distinction we speak of "private pensions" or "occupational pensions".
} 
recent years financial instability of "pay-as-you-go" first pillar funds led to significant reductions in the generosity of pension systems in Europe, furthermore many Countries replaced Defined Benefit schemes with Defined Contribution schemes (also within the first pillar). These changes may have enhanced differences due to the former occupational status and job-seniority of retirees, potentially boosting inequalities.

In this paper we document the redistributive features of the public (first pillar) pension systems in several European countries by making use of a summary measure of Social Security Wealth (SSW) computed at the individual level. Our measure, developed in Belloni et al. (2016), is based on the definition used in Feldstein (1974), Stock and Wise (1990), and more recently in the volumes edited by Gruber and Wise (1998, 2004, 2007). We make use of the SHARE data (Survey of Health Ageing and Retirement in Europe), a longitudinal dataset based on a representative sample of individuals aged 50 or over living in Europe. The SHARE questionnaire collects extensive information on a variety of aspects relevant to describe individual well-being, ranging from health conditions to economic resources. We will use the SSW measure presented by Belloni et al. (2016) and included in the fourth wave of SHARE, which has been obtained by combining individual-level information included in the third and the fourth waves of the survey. Whereas the fourth wave focuses on the situation of respondents at the time of the interview, the third wave (SHARELIFE) collects retrospective information on the main events occurring during their lives, including their work-histories.

While several studies have looked at the importance of Social Security for various dimensions of well-being at country level (see for example the different country-chapters 
of Gruber and Wise, 2004), very few authors have looked at a comprehensive study of the redistributive features of public pensions across Europe based on micro-data. Indeed, the possibility to carry out a pan-European study of individual-level social security wealth and the redistribution effects of pension policies has been limited by the lack of appropriate and fully comparable data ${ }^{3}$. One exception in this vast literature is represented by the periodical report by the OECD "Pensions at a Glance" (OECD, 2009, 2011 and 2013) as it provides an international comparative analysis of the features of pension systems, including benefit calculation rules and distributional effects, based on a synthetic "steady-state" population. In particular, the OECD Report also presents a "progressivity index", developed by Biggs et al. (2009) and based on inequality measures of SSW and earnings in order to assess the redistribution properties of Social Security Systems.

In this paper we calculate a progressivity index based on SHARE data along the lines of the OECD Report, thus producing aggregate measures of the pension system generosity for several European countries. However, the availability of high-quality micro-level data recorded in SHARE allows us to analyse the generosity of the different pension systems in a detailed way, for example in relation to the entire earnings distribution of individuals. The advantage is that we can investigate the actual determinants of the observed progressivity index obtained at the aggregate level and to assess whether and how the different pension systems protect the welfare of low earners. Finally, we look in a descriptive way - at the possible displacement effects of social security on private

\footnotetext{
${ }^{3}$ Important examples in close domains are Blau et al. (2006), Brandolini and Smeeding (2016) and Nolan et al. (2016).
} 
wealth by plotting the share of social security wealth over a comprehensive measure of wealth that aggregates total private wealth and social security wealth.

The paper is organized as follows. In Section 2 we provide the definition of our relevant measure of SSW and present the SHARE data, explaining how the information available at the individual level in SHARE can be used to generate SSW. Section 3 discusses the properties of the social security wealth estimates by making use of simple descriptive statistics. Section 4 first analyses the redistribution properties of the different pension systems at the country-level and then exploits the SHARE micro-data to study the degree of generosity of SSW along the lifetime labour income distribution of individuals. Section 5 investigates how SSW correlates with private household wealth and hints to a possible "substitutability" mechanism between these two forms of wealth. Section 6 provides some concluding remarks.

\section{Estimating Social Security Wealth in the SHARE sample}

This paper is based on a summary measure of the generosity of the social security system known as social security wealth (SSW) that has been widely used to deal with several research questions in pension economics, such as retirement behavior (see, e.g. Stock and Wise 1990), the crowding out of private savings (Gale, 1998; Attanasio and Brugiavini, 2003; Kapteyn et al., 2005, Alessie et al 2013), and as a general measure of the implicit liabilities of a government vis-à-vis its current and future retirees (Holzmann et al., 2004). 
Although the original concept of SSW dates back to the seminal paper of Feldstein (1974) and is quite general, more recent contributions offer operational definitions that may vary substantially, especially if applied at the individual or household level. In this paper we exploit the measure of individual SSW developed in Belloni et al. (2016) based on the Survey of Health, Ageing and Retirement in Europe (SHARE) data. Belloni et al. (2016) provide the first attempt at delivering a set of internationally comparable measures of SSW computed at the individual level for a large number of countries. The SSW measure includes first pillar pension benefits plus minimum pension benefits (guaranteed flat benefits) when relevant, it does not include survivor benefits, it is based on pension benefits net of income $e^{4}$ and payroll taxes, and it is measured in 2010 Euros $^{5}$.

Two specifications of SSW are typically adopted in the literature, depending on the individual's labor market status at the time of the interview. We stick to this literature and define the SSW of retired respondents (retired from the labor market) as follows:

$S S W_{i}=\sum_{j=a}^{\Omega} P_{i, j} \pi(j \mid a)(1+r)^{a-j}$

where $i$ is the individual, $a$ is her/his age at the time of the interview, $\Omega$ is the maximum attainable age, $\pi($.$) are conditional survival probabilities according to current life tables$ and $r$ is a financial discount rate. $P$ is the self-reported public old age pension benefit annualized and net of pension income taxation. In this paper conditional survival

\footnotetext{
${ }^{4}$ SHARE release 6.0.0 Wave 4 provides two SSW variables: $S S W \_g w$ and $S S W \_n w$. They differ for individuals at work at the time of the interview. For the $\underline{S S W \_g w}$ variable the computation of pension benefits is based on generated grossed-up wages. In this paper we use $S S W \_g w$ and refer to it as SSW.

${ }^{5}$ All monetary in this paper values have been adjusted to take into account differences in the cost of living across countries by using purchasing power parity 2010 indexes. As a result, monetary values are expressed in 2010 "German" euros, i.e. the unit of measure is the quantity of goods that it was possible to buy in Germany with $1 €$ in 2010 .
} 
probabilities $\pi$ are taken from the Human Mortality Database ${ }^{6}$ and are Country and gender-specific. The maximum attainable age is set to 109. The discount rate $r$ is set to 2 percent as in OECD (2013).

The SSW of individuals who are still working at the time of the interview is defined as follows:

$S S W_{i}=\sum_{j=R}^{\Omega} \hat{P}_{i, j}(R) \pi(j \mid a)(1+r)^{a-j}$

where $\hat{P}(R)$ is the computed public old age pension benefit assuming that the individual will retire from the labor market at current age $a$, and she will start receiving pension income from the old age retirement age $R$. The variable $\hat{P}(R)$ is annualized and net of pension income taxation. Old age retirement $R$ is an institutional "contextual" variable that depends on country specific pension legislation, while maximum attainable age, survival probabilities and the discount rate are defined as in the case of the retirees presented above ${ }^{7}$.

The SSW for workers is defined only if, at the time of the interview, minimum eligibility conditions for insurance or/and contribution years are met, but the worker is not yet age eligible for collecting a pension. In other words, we assume that the individual will retire at her current age, stop paying contributions to the pension system and receive a pension at a future age starting from the old age retirement age $R$. This allows us to interpret our measure as "accrued" SSW, as we do not make any projections of future labour supply and of future wages of workers in the sample but simply compute the pension rights

\footnotetext{
${ }^{6}$ www.mortality.org

${ }^{7}$ For some countries the old age retirement age $R$ is included, as contextual variable, in the second release of the SHARE Job Episode Panel, as documented in Antonova et al., 2014.
} 
based on the past and current contributions. If minimum eligibility conditions in terms of contributory years are not met at the time of the interview, the worker is simply dropped from the sample. While this approach is coherent with the definition of accrued pension wealth, it neglects relevant cases of workers who do not meet the minimum age requirements past age 50, typically workers characterized by discontinuous working careers: a pattern which is prevalent for women.

Data are taken from the SHARE survey, a multidisciplinary, cross-national longitudinal database of micro data on health, socio-economic status and social and family networks. The SHARE sample is representative of the populations of individuals aged 50 or over living in 20 European countries (plus Israel) ${ }^{8}$ and their spouses. Six waves of SHARE are currently available. The first two and the last three waves focus on the condition of respondents at the time of the interview. The third wave (SHARELIFE) is a retrospective survey that uses life-history interviews to gather information about the main events occurred throughout respondents' lives with respect to family relationships, employment, health-status, health care and housing ${ }^{9}$. Our sample consists of individuals who are interviewed in both the Wave 4 of SHARE, which has been mainly collected in 2011, and in SHARELIFE, which has been collected between 2008 and 2009.

\footnotetext{
${ }^{8}$ See Börsch-Supan et al. (2013a and 2013b) and Malter and Börsch-Supan (2013) for more information on the SHARE data.

${ }^{9}$ See Börsch-Supan et al. (2011) and Schröder (2011) for more information on the contents and the methodology of the life-history interviews conducted in the SHARELIFE surveys.
} 
The distinction between workers and retirees is based on a question present in the fourth wave of SHARE, asking about the current job situation ${ }^{10}$. Information on pension benefit, necessary to compute SSW as in equations (1) and (2), is obtained in different ways for retirees and for workers, respectively. In the former case the pension benefit is observed in the data and can be readily inserted into the definition of SSW. In particular, the relevant question asks about a typical - after taxes - payment of public old age pension in the previous year. The amount is an ordinary typical-regular payment, excluding any extras, such as bonuses, 13th month etc. For workers, the (expected) pension amount they will receive at retirement needs to be computed. This is a complex task since pension benefit computation rules are country specific. Belloni et al. (2016) rely on Mutual Information System on Social Protection tables (MISSOC, version July 2010) to define the appropriate pension rules for each country, plus information obtained directly from country specific publications. This calculation often requires the reconstruction of the individual working life as well as of the contribution rates and pension rules that were in place in the past. Retrospective individual data like wage history, insurance and contribution years and/or residential information needed to compute the pension benefit have been mainly obtained from the Job Episodes Panel (JEP). The JEP is a dataset based on SHARELIFE and it runs until 2008. It is a retrospective panel dataset in which respondents contribute as many observations as their years of age at the moment of the SHARELIFE interview. This panel stores information about the lifetime evolution of respondents' working conditions, ranging from labor market status to wages and

\footnotetext{
${ }^{10}$ The question allows for six possible, mutually exclusive, answers: 1. Retired, 2. Employed or selfemployed (including working for family business) 3. Unemployed, 4. Permanently sick or disabled, 5. Homemaker, 97. Other (Rentier, Living off own property, Student, Doing voluntary work).
} 
job-specific characteristics. ${ }^{11}$ Although the JEP runs until 2008, our SSW measure for workers is based on their entire working history up to 2010 in order to exploit the information collected in the wave 4 of $\mathrm{SHARE}^{12}$. Consistently, the pension rules considered to compute the public old age pension benefits are those in place in 2010 . Wages and relevant information for years 2009 and 2010 needed to compute the SSW measure are recovered from SHARE Wave 4.

Our analysis is based on individuals living in the following twelve European countries: Sweden, Denmark, the Netherlands, Belgium, France, Germany, Switzerland, Austria, Spain, Italy, Poland and Czech Republic. Estonia, Hungary, Portugal and Slovenia did not take part to the third wave of SHARE (SHARELIFE), and therefore SSW can be computed only for retirees and not for workers. As a consequence, those countries are excluded from the investigation. We also excluded SHARE respondents residing in any of the twelve chosen countries who did not participate to the retrospective wave SHARELIFE or respondents displaying missing values in any of the relevant variables ${ }^{13}$. Finally, we excluded individuals aged 75 and above in 2010. This is because older pensioners in our sample may have retired at very different ages and may have experienced several pension regimes, hence the comparisons of the aggregate SSW may be largely affected by sample composition as well as differences in mortality. The final sample contains 2,603 workers and 5,124 retirees.

\footnotetext{
${ }^{11}$ See Brugiavini et al. (2013) for more details.

${ }^{12}$ In SHARE Wave 4 the income amounts collected refer to the year previous the interview.

${ }^{13}$ To limit the presence of outliers in the monetary variables used throughout the paper we drop the observations reporting amounts lower than the first percentile and higher than the ninety-ninth percentile.
} 
The analysis is carried out separately by gender and working status (distinguishing between workers and retirees). As for the former, the historical differences in labour market participation and in earnings-profiles between males and females as well as gender differences in pension rules, provide a strong argument in favour of carrying out separate analyses, The latter distinction between workers and retirees is due to the fact that, as described earlier, the definition of SSW is different for the two groups: for retirees we rely on self-reported pension benefits collected in the fourth wave of SHARE, while for workers we compute pensions on the basis of individuals' working career information collected in SHARELIFE and applying 2010 country-specific pension system rules.

\section{Social Security Wealth in Europe: descriptive statistics}

SHARE is the ideal dataset to study the redistributive features of social security systems across Europe since it is based on exactly the same set of questions and the same wording in all countries. Table 1 reports the number of individuals by country, gender and labor market status at the time of the interview (workers vs. retirees) included in our final sample. The number of retirees is much higher than the number of workers due to the reference population of the SHARE sample, consisting of individuals aged 50 or over and their spouses.

\section{TABLE 1 HERE}

Table 2 reports the sample size by cohort, gender and labor market status at the time of the interview. As pointed out earlier, we selected individuals born between 1935 and 
1960 (i.e. respondents aged 50 to 75 in 2010). The reason why we perform a sample selection based on age is twofold: on the one hand, we want to reduce the excessive heterogeneity in pension outcomes of different generations due to the different regimes experienced by the retirees, on the other hand we want to limit the effect of selectivity bias and attrition due to mortality.

TABLE 2 HERE

FIGURE 1 HERE

Figure 1 shows the distribution of our SSW measure by age and labour market status. As expected the distribution is left-skewed, females show a slightly higher prevalence of lower values and a more concentrated distribution with two distinct spikes. A clear difference emerges between the distribution of SSW for workers and the distribution for retirees: a result which is in line with the definition of accrued SSW and with the fact that we observe more retirees than workers. The dispersion of the SSW values can be due to a variety of factors, such as heterogeneity in earnings as well as in the length of the working careers. Moreover, the eligibility and benefit computation rules relevant for the retirees in our sample have changed over time.

FIGURE 2a HERE

FIGURE $2 b$ HERE

Figures $2 \mathrm{a}-2 \mathrm{~d}$ show the box plots of SSW in the four samples of interest by country: male workers $(2 a)$, female workers $(2 b)$, male retirees $(2 c)$ and female retirees $(2 d)$. As reported above, all monetary amounts considered in the paper have been PPP-adjusted so that they are fully comparable across countries. Stark differences in the level of SSW 
emerge across countries: Figure 2a shows that Poland has the lowest median SSW for male workers, around $35,000 €$, which is due to both low median annual pension benefits (about 3,700€) and low life expectancy (male life expectancy at the age of eligibility 65 is 14.69 years). Comparable median values of SSW (around 100,000€) are observed in Germany, The Netherlands, Belgium, France, Switzerland, Spain, Italy and Czech Republic, while Sweden and Austria are characterized by somewhat higher median values (around 150,000€). In terms of variability in SSW, Figure 2a highlights a clear dichotomy. Poland, Denmark, The Netherlands and Switzerland display a very small interquartile range, while the SSW variation looks much higher in the remaining countries. As documented by Figure 2b, this ranking and clustering of countries is overall similar for female workers with a few noticeable exceptions, such as Germany, where the level and the variability in SSW for women is lower than what is observed for men and France, where a higher concentration prevails for female workers.

FIGURE 2c HERE

FIGURE 2d HERE

It is harder to identify a pattern across countries according to the median level of SSW in the case of retirees. This result is likely due to the fact that more cohorts are included in the sample of retirees than in the sample of workers, which mechanically generates heterogeneity for unconditional summary measures. In fact, different cohorts have experienced different business-cycle conditions during their working history and have been exposed to different pension eligibility and benefit computation rules in place at the time of retirement. These issues suggest caution in the interpretation of results based on median values, however some meaningful comparisons can be proposed. Looking at the 
median SSW of retirees in Figure 2c and 2d we observe that Germany, Belgium, France and Switzerland median SSW for retirees is noticeably higher than in the case of workers, suggesting that these countries enacted significant pension reforms aimed at curtailing public spending.

It should be noted that our measure of SSW is based on old-age public (first pillar) pension. Although in some cases the role of occupational pensions may be relevant, in this paper we want to describe the provisions that individuals are entitled to in terms of first-pillar social security as this is normally under the direct control of the State and therefore is the natural policy instrument to redistribute resources ${ }^{14}$. Table 3 reports the proportion of individuals receiving an old age first pillar pension who also receive an occupational-pension benefit. Second-pillar provisions are prevalent in Sweden, The Netherlands, Denmark and Switzerland; results from SHARE on these percentages are in line with what reported by other sources, such as OECD (2016), hence suggesting that the public provisions are the most relevant pension income, at least in terms of coverage, and are correctly measured in SHARE.

\section{Inequality and progressivity of social security}

One objective of our study is to highlight how differences in SSW across countries may reflect differences in the generosity of the social security systems (including minimum pensions), as well as differences in lifetime earning profiles. The interplay between these

\footnotetext{
${ }^{14}$ The OECD "Pensions at a Glance" pension models include all mandatory pensions schemes for privatesector workers, regardless of whether public (i.e. they involve payments from government or from social security institutions, as defined in the System of National Accounts) or private.
} 
features is embedded in the pension formula: for instance, in the Netherlands, the first pillar benefit (AOW) depends mostly on residential life histories and does not depend on earning life histories (Kapteyn and de Vos, 1999). At the other extreme, the German social security provisions (“earnings points system”, Börsch-Supan and Wilke, 2006) are fully based on lifetime relative earnings. In this section we will use SHARE data to assess to what extent the cross-country differences in SSW dispersion previously documented are a result of cross-country differences in the volatility of lifetime earnings or they reflect different architectures of the pension system in each country. Disentangling these two sources of heterogeneity is essential to understand the contribution of the pension systems in shaping within-country SSW inequality.

Besides presenting descriptive evidence on social security wealth, which is interesting per se, we want to measure in a simple way the degree of redistribution present in Europe which can be explained by the social security system carrying out comparisons across countries and within each country. In order to provide this type of evidence for pension provisions we make use of well-known measures such as the Gini coefficient (G-index), computed at the country-gender-occupation level and based on individual estimates of social security wealth. However, the observed inequality in SSW among countries and groups as measured by the G-index can be due both to heterogeneity in the institutional characteristics of social security systems and to differences in the lifetime earnings distribution, hence we also consider a measure of lifetime resources such as the average lifetime income (ALTI). This measure should provide a full life-course perspective of inequality and control for individual resources by distinguishing the lifetime-rich from the lifetime-poor individuals. Following Biggs et al. (2009) and the OECD (2009, 2011, 
2013), we also consider a progressivity index, which is designed to capture the redistribution within the system from low-earners to high-earners.

\subsection{Country-level measures of inequality}

In order to provide cross-countries evidence on inequalities in pension provisions we make use of the G-index based on our estimates of SSW at the individual level, computed separately by country, gender and occupational status. Our approach is similar to the exercise carried out by the OECD (2009, 2011, 2013). However, some relevant differences should be mentioned. We focus our analysis on an estimate of SSW computed at the individual level for an actual sample of individuals obtained from micro data: the selected individuals are SHARE-respondents at a given point in time, hence encompassing a large set of cohorts - part of which are still at work and part are already retired at the time of the interview- rather than making reference to a steady-state "virtual" population. We make use of country-specific and gender-specific life expectancy rather than a population-wide life expectancy. Another important difference is that while we consider separately workers and retirees and measure actual accrued SSW (as detailed below), the OECD computes total SSW for a continuous career in the work-place (baseline scenario) referring to a "representative" individual of the population in one specific country. Finally, it should be stressed that our estimate of SSW for workers is a lower bound because it is the accrued SSW to date, so that it does not account for the entire wage growth over the life cycle. The same argument holds for retirees as, in agreement with the accrued-SSW definition, we do not take into account past benefits but only future expected benefits. 
We exploit information from the third wave of SHARE (SHARELIFE), which reports retrospective wages along the working history to compute Individual Average Life-Time Income (ALTI). This is defined as the total capitalized sum of annualized earnings received over the whole working history, divided by the number of years individuals have worked, expressed in 2010 euros ${ }^{15}$. We argue that ALTI is a meaningful indicator to summarize individual's position in the earnings distribution as it standardizes earnings with respect to the entire working history and it neutralizes the effect of the length of the career of individuals.

\section{FIGURE 3 HERE}

Figure 3 reports the distribution of the ALTI by gender and employment status. As in the case of SSW, the distribution in all subsamples is skewed with a rather long right tail.

\section{TABLE 4 HERE}

Results on the measures of inequality are reported in Table 4, where we present the Gcoefficient for SSW and the progressivity index. The latter is designed to summarize in a single value the extent of the redistribution properties embedded in the social security system rules. It provides a natural ranking of pension systems in terms of redistributive properties: when social security redistributes resources from higher- to lower-earning groups it is regarded as progressive. Two are the key ingredients needed to calculate a progressivity index: an inequality index for SSW and an inequality index for an appropriately defined measure of lifetime earnings (ALTI). The progressivity index is

\footnotetext{
${ }^{15}$ Because of the nature of the data, we have to assume that wages are constant in real terms within each past job spell, which delivers a lower bound measure of lifetime income at the individual level, as part of the within-spell growth is neglected.
} 
defined as the difference between 1 and the ratio between the G-index for SSW and the G-index for ALTI, normalized to 100. The lower the inequality in SSW compared to the inequality in average lifetime income, the higher is the progressivity of the pension system and the higher the progressivity index. It varies from 100 in pure flat schemes (maximum redistribution) to negative for regressive pension systems.

In order to correctly interpret the progressivity index, one has to take into account that the same pension system can be found to be more progressive/regressive in our data depending on the underlying income distribution to which pension rules are applied. Therefore, a meaningful comparison of the index across countries can be performed for countries with similar values of the G-index for ALTI, which is why we also report the G-index performed on ALTI as well.

Table 4 shows that the G-index of SSW (first columns) is characterized by a marked cross country variability: a striking difference emerges for German male workers vis-avis Danish or Swiss workers, the gap is even wider for women. If we turn the attention to retirees, we find that in many countries inequality is higher than among workers and that it is highest in Belgium and lowest in the Netherlands. Cross-country heterogeneity in average lifetime income inequality is also substantial. For instance, the G-index for ALTI for Polish retirees is respectively two and three times higher than the values found for their Swedish and German counterparts. These simple cross-country comparisons can provide some insight of the role played by the pension system architecture in shaping the SSW inequality. Consider the case of male workers in Austria and Denmark: the G-index in ALTI is the same but the SSW inequality in Austria is much higher, (three times higher) than the one found in Denmark. As a result the progressivity index for male 
workers is equal to 78.26 and 21.74 respectively. Conditioning on the same level of inequality in ALTI, the Danish pension system appears to be more redistributive than the one in place in Austria. Germany and Belgium present similar levels of inequality in ALTI of male workers, but their progressivity indexes show wide variation: -57.69 for Germany, 42.86 for Belgium. Keeping earnings inequality constant, the Belgian pension system is more redistributive than the German one ${ }^{16}$.

\subsection{Within-country measures of inequality}

The analysis based on the progressivity index provides an overall country-level measure of redistribution (separately by gender and employment status) determined by the pension system. However, it is limited in scope as it does not provide information on which part of the earnings distribution is more affected by the public pension redistributive rules and it cannot be used to assess the extent to which the pension system of a given country protects individuals who are "lifetime poor" vis-à-vis those who are "lifetime rich".

In order to provide a more accurate representation of inequality and to disentangle the "pension rules" effect from the "lifetime-earnings distribution" effect at the individual level, we propose a new simple index of Relative Social Security Wealth (RSSW) given

\footnotetext{
${ }^{16}$ We computed the relevant indexes also making use of LTI (Lifetime Income), i.e. the capitalized sum of earnings, which is just the numerator of ALTI. The LTI would greatly enhance differences in career length rather than actual earnings, on the other hand ALTI may generate a similar number for a low-wage worker who worked many years and a high-earner who worked a few years. Figure A.1 reports the distribution of LTI, which is more dispersed than ALTI due to the fact that it encompasses variability in earnings and length of working career. As for the inequality measures the country ranking is preserved and our results are confirmed (Table A. 1 in the Appendix).
} 
by the ratio between Social Security Wealth (SSW) and Average LifeTime Income (ALTI):

$$
\mathrm{RSSW}=\mathrm{SSW} / \mathrm{ALTI}
$$

Although the spirit is similar to the concept behind the progressivity index, we stress that in our analysis both measures are computed at the individual level, so that we obtain a measure of RSSW for each individual in the sample.

We argue that RSSW can be informative of the redistributive features of the pension systems since it shows to what extent the SSW of an individual compares to the average labor income she earned during her whole working career, which is positively related to the average amount of yearly contributions paid to the social security administration. The higher is the SSW of a worker relatively to her average lifetime income, the higher is the generosity of the pension system for this worker. The standardization of SSW with respect to ALTI, both taken at the individual level, allows for a meaningful comparison of the "pension generosity" between groups and countries. However, one aspect of caution is the effect of birth-cohort and age on SSW and ALTI, which then may affect both the numerator and denominator of RSSW. Our sample involves individuals from different birth-cohorts who might have been exposed to different pension regimes, which were often phased in according to age or year-of-birth of workers either by explicit design or simply because of the timing of maturity or vesting of benefits. Furthermore, individuals from different birth-cohorts might have faced different phases of the business cycle in different stages of their working careers producing cohort-differentials in their earnings age profiles. Any meaningful analysis of the determinants of RSSW should control for cohort/age effects. 
We can assess the redistributive properties of pension systems along the average lifetime income distribution of individuals. Our exercise documents how the generosity of the pension rules varies with individual average lifetime earnings and is successful in granting higher level of protection to workers who are "lifetime poor", i.e. workers whose ALTI appears in the left tail of the distribution. To do this, we predict the median ratio RSSW at each average lifetime income quintile by performing a set of country-specific median regressions for the four samples of interest. Since we are dealing with crosssectional data it is not possible to disentangle birth-cohort from age effects. However, we allow for RSSW to vary among cohorts/ages by including in the regressions a set of cohort dummies as shown in Table 2.

TABLE 5 HERE

Table 5 reports the fitted median of the RSSW ratio for workers, by country of residence, quintile of average lifetime income (from Q1, lower quintile to Q5, higher quintile) and gender.

\section{FIGURE 4 HERE}

Figure 4 presents the same results in graphical terms focusing on Germany: quintiles of lifetime income ALTI are on the X-axis and the ratio RSSW is on the Y-axis. Germany is characterised by a very limited pension income redistribution as the fitted RSSW ratio remains constant throughout the whole lifetime income range. This finding shows that, conditional on birth-cohort, the SSW of German workers varies proportionally with their average lifetime income so that the same inequality observed in lifetime earnings is to a large extent reflected in pensions. 


\section{FIGURE 5 HERE}

A different picture emerges for Spain and Italy (Figure 5) as there exists a clear gradient. The RSSW of Spanish male workers exhibits a huge drop between the first and the second quintile (50 percentage points) followed by a modest reduction at the higher quintiles. A similar pattern is found for women. These findings suggest that the Spanish pension system operates a significant redistribution in favour of lower lifetime-earnings individuals. The ratio between SSW and ALTI of Spanish workers in the left tail is higher than in the right tail. Similar results are found for Italian women: the ratio of SSW to average lifetime earnings of female workers decreases by 48 percentage points between the first and second quintile of the earnings distribution and it remains overall flat afterwards. This pattern is less marked for Italian men.

\section{FIGURE 6 HERE}

Figure 6 shows that a third welfare model emerges for Denmark and the Netherlands. In these countries, the profile of the median RSSW index appears to be steadily decreasing over the whole earnings distribution. Focusing on the Danish male workers, we notice that the ratio constantly decreases by 20 percentage points at each quintile.

\section{TABLE 6 HERE}

Table 6 summarizes the results for retirees: we can cluster countries into two groups. A first group including Germany, Belgium, Switzerland and the Czech Republic, in which the SSW/ALTI ratio displays a moderate decline between the first and second quintile and a second group where RSSW declines significantly between the first two quintiles.

\section{FIGURE 7 HERE}


Our estimates capture in an effective way how pension rules have affected different birthcohorts of workers and retirees: Germany is an interesting case in this respect. The profile of the RSSW index for German workers - as shown in Figure 3 - is basically flat, in line with the rules used to compute pension benefits according to the current German pension system, which sets the benefit amount equal to the product between the ratio of individuals' earnings on the average national earnings times a coefficient proportional to the length of contributing history. Figure 7 reports that the ratio for retirees is steadily decreasing over earning quintile values. Figure 7 confirms German retirees are entitled to levels of pensions (and SSW) that accrued according to the pre-reform rules: the declining ratio suggests the presence of redistribution mechanisms in favor of current retirees experiencing lower earnings during their working history.

\section{Social Security Wealth, Financial Wealth and Real Wealth}

In the previous sections we focused the attention on inequalities in a SSW measure based on first-pillar pensions. However, this is a partial view of the resources available to individuals and households, as it neglects private wealth holdings. In this section, we attempt an estimate of the correlation between SSW with other forms of private household wealth. Forward-looking agents who expect lower levels of SSW might have stronger incentives to save and cumulate private wealth in order to guarantee adequate standards of living during their retirement years (see, e.g., Alessie, Angelini, Van Santen, 2013; Attanasio and Brugiavini, 2003). This is a relevant point for policy makers since the design of Social Security Systems may result in a variety of household economic choices related to financial and real wealth investments, including participation to 
financial markets and home-ownership. Households endowed with higher levels of SSW might be less prone to participate in financial markets or to save in order to buy a house because they know that the wealth accrued in the Social Security System will be an effective safety net protecting their standard of living at older ages. Some authors have discussed of an actual "displacement effect" of SSW on private wealth holdings or on the saving rate (Feldstein, 1974; Dicks-Mireaux and King, 1984; Attanasio and Brugiavini, 2003; Blau, 2006). Whether SSW actually produces a displacement effect on financial and real wealth is an empirical issue that requires a comprehensive theoretical framework explicitly designed to model lifetime accumulation of private wealth, insurance contracts and old-age protection instruments. Such a complex model is beyond the scope of this paper, but even in this simplified framework we can exploit the detailed information provided by the Wave 4 of SHARE about household financial and real wealth to provide descriptive evidence about the relationship between SSW and private wealth of older European individuals.

SHARE data contain household measures of net financial and real wealth. Net financial wealth is defined as the sum of money held by households in bank accounts, stocks, bonds, mutual funds and savings for long-term investments, net of financial liabilities. Net real wealth is the value of the main residence, of other real estates and of businesses, net of mortgages. Since financial and real wealth in SHARE are measured at the household level, their comparison with the SSW requires the latter to be defined at the household level as well. We construct a household level measure of SSW that is defined as the sum over household members of individual SSW. We denote this measure of Household Social Security Wealth by HSSW. Note that in doing so we avoid double 
counting as our definition of SSW does not include survivors' benefits and spousal benefits. We can think of our estimate of HSSW as a lower bound for the effective social security wealth available to the households.

\section{TABLE 7 HERE}

Table 7 reports the quintiles of the sample distribution of the household level measures of SSW, real assets and financial assets. Amounts are expressed in thousands of 2010 euros for all countries and PPP-adjusted to account for country level differences in the cost of living ${ }^{17}$. In order to assess whether HSSW is negatively associated with lower levels of financial and real wealth, we introduce the concept of total household wealth as the sum of HSSW, financial wealth and real wealth measures. This definition allows us to compute the shares of private wealth and social security wealth.

\section{FIGURE 8 HERE}

\section{FIGURE 9 HERE}

In Figure 8 and Figure 9 we plot the country-level averages of the share of total household wealth held in SSW against the corresponding share of total household wealth held in financial and real wealth respectively.

FIGURE 10 HERE

FIGURE 11 HERE

\footnotetext{
${ }^{17}$ To align with the age restriction previously used, we dropped singles older than 75 and couples where both couple members are older than 75 . We also still drop observations reporting values of SSW lower than the first percentile and higher than the ninety-ninth percentile.
} 
Figures 10 and 11 repeat the same analysis at regional level (NUTS-1) in order to account for geographic differences in wealth accumulation. This disaggregation reveals substantial differences in the within-country variation of the composition of total household wealth. As an example, Poland exhibits higher dispersion in the share of HSSW and limited dispersion in the share of financial wealth. France is characterized by a high within-country variability in the share of financial wealth, while Germany exhibits significant within-country variability for both the shares of HSSW and financial wealth.

Although we cannot draw conclusions on the likely "substitutability" between the two forms of wealth, a clear negative gradient is estimated both within and between countries regardless of whether real wealth or financial wealth is used. When looking at the country-level evidence in Figures 8 and 9, it emerges that the total wealth of Danish and Swiss households is characterized by low shares of HSSW and high shares of private financial and real wealth. At the other extreme, total wealth of Austrian and Polish households relies more greatly on HSSW and less on private wealth holdings. It is interesting to note that Italian and Spanish households qualify as "house-rich" since more than $50 \%$ of private wealth is held in real assets (housing) while a residual part is invested in financial markets. According to our findings, a lower share of total wealth held in Household Social Security Wealth is on average associated with a higher share of wealth held in financial and real assets. As expected, this negative relationship appears to be stronger for financial wealth than for real wealth, as financial wealth is more "fungible", so that it can be easily decumulated during retirement.

\section{Conclusion}


In this paper we investigate the distribution of old-age resources for a large number of European countries by making use of the SHARE data. We present a novel estimate of Social Security Wealth (SSW), which is computed at the individual level on SHARE data, and argue that this is an effective summary indicator of the resources that individuals could have access to in their old age. Our SSW measure is very detailed as it is based on the pension rules in place in each country in different points in time, and embeds country and gender specific mortality patterns, taking a lifetime perspective. Building upon this new measure, we are able to look at traditional inequality indexes: some countries show low median values of SSW but also very little variability over the possible range of values taken by the SSW, such as Denmark and to some extent the Netherlands. At the other extreme we observe countries, such as Italy and Spain, where the dispersion of SSW is much higher.

Cross-country and within-country differences in SSW inequality might depend on different architectures of the pension systems as well as on heterogeneity in individual characteristics, in particular the amount of earnings collected during the working career. In order to control for individual heterogeneity due to differences in lifetime earnings, we exploit the information from SHARE to compute individuals' Average Life Time Income (ALTI). We compute a progressivity index along the lines of the OECD Reports (2009, 2011 and 2013) that compares inequality levels in Social security wealth and Average Lifetime Income in order to measure the degree of redistribution in SSW generated by the pension systems. A refinement of this is to "anchor" our measure of SSW to the distribution of average lifetime income. More precisely, we introduce a Relative Social Security Wealth (RSSW), defined as the ratio of SSW over ALTI, in the attempt to shed 
light on the redistributive features of pension systems controlling for average labour income over whole working career. In fact, ALTI is positively related to the average amount of yearly contributions paid to the social security administration and could enter directly and indirectly into the pension formula. The higher is the SSW of a worker relatively to her average lifetime income earned (and the contributions paid), the higher is the generosity of the pension system for this worker.

We present the distribution of RSSW ratio over the quintiles of average lifetime income and show that in countries such as Denmark, The Netherlands and Spain individuals whose working history is characterized by low levels of ALTI are also characterized by high levels of the RSSW ratio. In these countries the pension system is progressive. In other countries, such as Germany, the current pension system appears to be more regressive.

Finally, we provide descriptive evidence of a household-level analysis of the interrelation between social security and private wealth. We show that in those countries where the first pension pillar is relevant, the share of total household wealth allocated in social security wealth is much higher. Although we cannot draw firm causality conclusions on the displacement effect of SSW on private wealth, the clear negative correlation that we obtain suggests that households who feel more protected by the welfare state are expected to cumulate lower levels of private real and financial assets. 


\section{References}

Alessie, Rob, Viola Angelini and Peter Van Santen. (2013). "Pension Wealth and Household Savings in Europe: Evidence from SHARELIFE." European Economic Review, 63: 308-328.

Attanasio, Orazio and Agar Brugiavini. (2003). "Social Security and Households' Saving." The Quarterly Journal of Economics, 118(3): 1075-1119.

Antonova, Liudmila, Luis Aranda, Giacomo Pasini and Elisabetta Trevisan. (2014). "Migration, Family History and Pension: The Second Release of the SHARE Job Episodes Panel.” SHARE Working Paper Series 18-2014.

Belloni, Michele, Ludovico Carrino, Cristina E. Orso, Raluca E. Buia, Danilo Cavapozzi, Giacomo Pasini and Agar Brugiavini. (2016), "Internationally Comparable Measures of Individual Social Security Wealth in SHARE Wave 4." SHARE Working Paper Series 24-2016.

Biggs, Andew G,, Mark Sarney, and Cristopher R. Tamborini. (2009). “A Progressivity Index for Social Security.” Issue Paper No. 2009-01, Social Security Administration, USA.

Blau, Francine D., Marianne A. Ferber and Anne E. Winkler, Editors. (2006). The Economics of Women, Men and Work. 5th ed. Englewood Cliffs, NJ: Prentice Hall.

Börsch-Supan, A., and C. Wilke (2006). 'The German Public Pension System: How It Will Become an NDC System Look-Alike', in R. Holzmann and E. Palmer, eds., Pension 
Reform: Issues and Prospects for Non-Financial Defined Contribution (NDC) Schemes. Washington, DC: The World Bank: 573-610.

Börsch-Supan, Axel, Martina Brandt, Karsten Hank and Mathis Schröder, Editors. (2011). The Individual and the Welfare State. Life Histories in Europe. Heidelberg: Springer.

Börsch-Supan, Axel, Martina Brandt, Christian Hunkler, Throsten Kneip, Julie Korbmacher, Frederic Malter, Barbara Schaan, Stephanie Stuck and Sabrina Zuber. (2013a). "Data Resource Profile: The Survey of Health, Ageing and Retirement in Europe (SHARE).” International Journal of Epidemiology, 42(4): 992-1001.

Börsch-Supan, Axel, Martina Brandt, Howard Litwin and Gugliemo Weber, Editors. (2013b). Active Ageing and Solidarity between Generations in Europe: First Results from SHARE after the Economic Crisis. Berlin: De Gruyter.

Brandolini, Andrea and Timothy M. Smeeding. (2011). 'Income Inequality in Richer and OECD Countries', in B. Nolan, W. Salverda, and T. M. Smeeding, eds., The Oxford Handbook of Economic Inequality. Oxford UK: Oxford University Press.

Nolan, Brian, Wiemer Salverda and Timothy M. Smeeding, Editors. (2011). The Oxford Handbook of Economic Inequality. Oxford UK: Oxford University Press.

Brugiavini, Agar, Danilo Cavapozzi, Giacomo Pasini and Elisabetta Trevisan. (2013). "Working Life Histories from SHARELIFE: A Retrospective Panel." SHARE Working Paper Series11-2013. 
Dicks-Mireaux, Luis and Mervin A. King, (1984). "Pension Wealth and Household Savings: Tests of Robustness.” Journal of Public Economics, 23: 115-40.

Feldstein, Martin. (1974). "Social Security, Induced Retirement, and Aggregate Capital Accumulation.” Journal of Political Economy, 82(5): 905-926.

Gale, William G.. (1998). “The Effects of Pensions on Household Wealth: A reevaluation of Theory and Evidence." Journal of Political Economy, 106(4): 706-724.

Gruber, Jonathan and David A. Wise, Editors. (1998). Social Security Programs and Retirement around the World. Chicago: The University of Chicago Press, 1998.

Gruber, Jonathan and David A. Wise, Editors. (2004). Social Security Programs and Retirement around the World: Micro-estimation. Chicago: The University of Chicago Press, 2004.

Gruber, Jonathan and David A. Wise, Editors. (2007). Social Security Programs and Retirement around the World: Fiscal Implications of Reform. Chicago: The University of Chicago Press, 2007.

Holzmann, Robert, Robert Palacios and Asta Zviniene. (2004). "Implicit Pension Debt: Issues, Measurement and Scope in International Perspective." Social Protection Discussion Paper Series, Human Development Network, The World Bank.

Kapteyn, Arie, Rob Alessie, Annamaria Lusardi. (2005). "Explaining the Wealth Holdings of Different Cohorts: Productivity Growth and Social Security." European Economic Review 49(5): 1361-1391. 
Kapteyn, Arie and Klaas de Vos. (1999). 'Social Security and Retirement in the Netherlands'. in J. Gruber and D.A. Wise, eds., Social Security and Retirement around the World. Chicago US: University of Chicago Press: 269-303.

Malter, Frederic, Börsch-Supan, Axel, Editors. (2013). SHARE Wave 4: Innovations \& Methodology. Munich: MEA, Max Planck Institute for Social Law and Social Policy.

OECD, 2009. Pensions at a Glance 2009: Retirement-income Systems in OECD Countries. Paris: OECD Publishing.

OECD, 2011. Pensions at a Glance 2011: Retirement-income Systems in OECD and G20 Countries. Paris: OECD Publishing.

OECD, 2013. Pensions at a Glance 2013: OECD and G20 Indicators. Paris: OECD Publishing.

OECD, 2016. Society at a Glance 2016 OECD Social Indicators. Paris: OECD Publishing.

Schröder, Mathis, Editor. (2011). Retrospective Data Collection in the Survey of Health, Ageing and Retirement in Europe. SHARELIFE Methodology. Mannheim: Mannheim Research Institute for the Economics of Aging (MEA).

Stock J.H. and D.A. Wise (1990). “The Pension Inducement to Retire: An Option Value Analysis", in D. A. Wise, ed., Issues in the Economics of Aging. Chicago, US: University of Chicago Press: 205-230. 
Table 1. Number of observations by country, gender and labor market status at the time of the interview (SHARE selected sample, workers vs. retirees)

\begin{tabular}{l|ccc|ccc}
\hline Country & \multicolumn{3}{|c|}{ Retirees } & \multicolumn{3}{c}{ Workers } \\
\hline & Total & Males & Females & Total & Males & Females \\
\hline SE & 497 & 225 & 272 & 276 & 113 & 163 \\
DK & 423 & 211 & 212 & 451 & 202 & 249 \\
DE & 536 & 284 & 252 & 232 & 89 & 143 \\
NL & 459 & 232 & 227 & 299 & 137 & 162 \\
BE & 576 & 323 & 253 & 247 & 112 & 135 \\
FR & 598 & 295 & 303 & 258 & 116 & 142 \\
CH & 330 & 155 & 175 & 242 & 109 & 133 \\
AT & 236 & 112 & 124 & 44 & 21 & 23 \\
ES & 245 & 182 & 63 & 123 & 75 & 48 \\
IT & 350 & 198 & 152 & 152 & 71 & 81 \\
CZ & 298 & 112 & 186 & 154 & 72 & 82 \\
PL & 576 & 259 & 317 & 125 & 64 & 61 \\
Total & 5124 & 2588 & 2536 & 2603 & 1181 & 1422 \\
\hline
\end{tabular}

Table 2. Number of observations by cohort, gender and labor market status at the time of the interview (SHARE workers vs. retirees)

\begin{tabular}{ccc|ccc}
\hline \multicolumn{2}{c|}{ Retirees } & \multicolumn{3}{c}{ Workers } \\
\hline Cohort & Males & Females & Cohort & Males & Females \\
\hline $1935-1939$ & 876 & 697 & $1935-1947$ & 106 & 83 \\
$1940-1944$ & 1,032 & 960 & $1948-1950$ & 260 & 228 \\
$1945-1949$ & 578 & 640 & $1951-1953$ & 411 & 433 \\
$1950-1956$ & 102 & 239 & $1954-1956$ & 371 & 527 \\
$/$ & $/$ & $/$ & $1957-1960$ & 33 & 151 \\
\hline
\end{tabular}


Table 3. Percentage of individuals receiving an old age first pillar pension who also receive an occupational pension benefit

\begin{tabular}{|l|rr|rr|}
\hline \multirow{2}{*}{ Country } & \multicolumn{3}{|c|}{ Occupational pensions } \\
\cline { 2 - 5 } & \multicolumn{3}{|c|}{ Men } & Women \\
Austria & retirees & workers & retirees & workers \\
\cline { 2 - 5 } Germany & $15.79 \%$ & $0.00 \%$ & $6.40 \%$ & $5.56 \%$ \\
Sweden & $33.51 \%$ & $1.23 \%$ & $16.93 \%$ & $0.00 \%$ \\
Netherlands & $73.42 \%$ & $3.23 \%$ & $74.33 \%$ & $2.92 \%$ \\
Spain & $84.84 \%$ & $7.52 \%$ & $38.69 \%$ & $5.96 \%$ \\
Italy & $3.44 \%$ & $0.00 \%$ & $2.30 \%$ & $0.00 \%$ \\
France & $3.23 \%$ & $0.00 \%$ & $1.05 \%$ & $0.00 \%$ \\
Denmark & $3.31 \%$ & $0.00 \%$ & $1.05 \%$ & $2.00 \%$ \\
Switzerland & $41.52 \%$ & $3.85 \%$ & $33.86 \%$ & $1.40 \%$ \\
Belgium & $69.83 \%$ & $5.77 \%$ & $32.50 \%$ & $3.13 \%$ \\
Czech Republic & $4.57 \%$ & $2.00 \%$ & $3.27 \%$ & $1.59 \%$ \\
Poland & $0.65 \%$ & $0.00 \%$ & $0.44 \%$ & $0.00 \%$ \\
\cline { 1 - 4 } SOurce: Our & $0.00 \%$ & $0.00 \%$ & $0.00 \%$ & $0.00 \%$ \\
\hline
\end{tabular}

Source: our computations on SHARE data; note: category 6 "Occupational survivor pension from your spouse or partner's job" has been excluded. 
Table 4. Gini coefficients of SSW and of Average Lifetime Income (ALTI) and the progressivity index by country

\begin{tabular}{|c|c|c|c|c|c|c|c|c|c|c|c|c|}
\hline & \multicolumn{4}{|c|}{ Gini Index for_SSW } & \multicolumn{4}{|c|}{ Gini Index for_ALTI } & \multicolumn{4}{|c|}{ Progressivity Index } \\
\hline & \multicolumn{2}{|c|}{ Workers } & \multicolumn{2}{|c|}{ Retirees } & \multicolumn{2}{|c|}{ Workers } & \multicolumn{2}{|c|}{ Retirees } & \multicolumn{2}{|c|}{ Workers } & \multicolumn{2}{|c|}{ Retirees } \\
\hline & Men & Women & Men & Women & Men & Women & Men & Women & Men & Women & Men & Women \\
\hline SE & 0.30 & 0.32 & 0.19 & 0.29 & 0.30 & 0.31 & 0.42 & 0.41 & 0.00 & -3.23 & 54.76 & 29.27 \\
\hline DK & 0.05 & 0.05 & 0.21 & 0.18 & 0.23 & 0.27 & 0.33 & 0.39 & 78.26 & 81.48 & 36.36 & 53.85 \\
\hline $\mathrm{DE}$ & 0.41 & 0.48 & 0.26 & 0.34 & 0.26 & 0.28 & 0.28 & 0.29 & -57.69 & -71.43 & 7.14 & -17.24 \\
\hline NL & 0.08 & 0.09 & 0.19 & 0.12 & 0.24 & 0.32 & 0.37 & 0.41 & 66.67 & 71.88 & 48.65 & 70.73 \\
\hline $\mathrm{BE}$ & 0.16 & 0.19 & 0.60 & 0.59 & 0.28 & 0.25 & 0.36 & 0.33 & 42.86 & 24.00 & -66.67 & -78.79 \\
\hline FR & 0.19 & 0.14 & 0.27 & 0.36 & 0.31 & 0.30 & 0.73 & 0.78 & 38.71 & 53.33 & 63.01 & 53.85 \\
\hline $\mathrm{CH}$ & 0.05 & 0.04 & 0.21 & 0.25 & 0.22 & 0.28 & 0.27 & 0.31 & 77.27 & 85.71 & 22.22 & 19.35 \\
\hline $\mathrm{AT}$ & 0.18 & 0.22 & 0.31 & 0.39 & 0.23 & 0.37 & 0.42 & 0.42 & 21.74 & 40.54 & 26.19 & 7.14 \\
\hline ES & 0.26 & 0.20 & 0.27 & 0.28 & 0.38 & 0.42 & 0.66 & 0.65 & 31.58 & 52.38 & 59.09 & 56.92 \\
\hline IT & 0.24 & 0.21 & 0.26 & 0.35 & 0.29 & 0.31 & 0.52 & 0.58 & 17.24 & 32.26 & 50.00 & 39.66 \\
\hline $\mathrm{CZ}$ & 0.14 & 0.15 & 0.22 & 0.20 & 0.25 & 0.31 & 0.29 & 0.24 & 44.00 & 51.61 & 24.14 & 16.67 \\
\hline PL & 0.20 & 0.11 & 0.25 & 0.24 & 0.84 & 0.49 & 0.92 & 0.92 & 76.19 & 77.55 & 72.83 & 73.91 \\
\hline
\end{tabular}


Table 5. Fitted median and percentage variations from the first quintile (in parentheses) of the RSSW index by country of residence, quintile of ALTI, and gender - workers

\begin{tabular}{|c|c|c|c|c|c|c|c|c|c|c|}
\hline \multicolumn{6}{|c|}{ WORKERS - MEN } & \multicolumn{5}{|c|}{ WORKERS - WOMEN } \\
\hline Country & Q1 & Q2 & Q3 & Q4 & Q5 & Q1 & Q2 & Q3 & Q4 & Q5 \\
\hline $\mathrm{SE}$ & 9 & $\begin{array}{c}7 \\
(-22 \%)\end{array}$ & $\begin{array}{c}7 \\
(-22 \%)\end{array}$ & $\begin{array}{c}7 \\
(-22 \%)\end{array}$ & $\begin{array}{c}7 \\
(-22 \%)\end{array}$ & 12 & $\begin{array}{c}7 \\
(-42 \%)\end{array}$ & $\begin{array}{c}7 \\
(-42 \%)\end{array}$ & $\begin{array}{c}7 \\
(-42 \%)\end{array}$ & $\begin{array}{c}8 \\
(-33 \%)\end{array}$ \\
\hline DK & 3 & $\begin{array}{c}3 \\
(0 \%)\end{array}$ & $\begin{array}{c}2 \\
(-33 \%)\end{array}$ & $\begin{array}{c}2 \\
(-33 \%)\end{array}$ & $\begin{array}{c}1 \\
(-67 \%)\end{array}$ & 6 & $\begin{array}{c}4 \\
(-33 \%)\end{array}$ & $\begin{array}{c}3 \\
(-50 \%)\end{array}$ & $\begin{array}{c}2 \\
(-67 \%)\end{array}$ & $\begin{array}{c}2 \\
(-67 \%)\end{array}$ \\
\hline $\mathrm{DE}$ & 3 & $\begin{array}{c}4 \\
(33 \%)\end{array}$ & $\begin{array}{c}4 \\
(33 \%)\end{array}$ & $\begin{array}{c}4 \\
(33 \%)\end{array}$ & $\begin{array}{c}4 \\
(33 \%)\end{array}$ & 3 & $\begin{array}{c}3 \\
(0 \%)\end{array}$ & $\begin{array}{c}3 \\
(0 \%)\end{array}$ & $\begin{array}{c}3 \\
(0 \%)\end{array}$ & $\begin{array}{c}4 \\
(33 \%)\end{array}$ \\
\hline NL & 8 & $\begin{array}{c}5 \\
(-38 \%)\end{array}$ & $\begin{array}{c}4 \\
(-50 \%)\end{array}$ & $\begin{array}{c}3 \\
(-63 \%)\end{array}$ & $\begin{array}{c}2 \\
(-75 \%)\end{array}$ & 16 & $\begin{array}{c}10 \\
(-38 \%)\end{array}$ & $\begin{array}{c}8 \\
(-50 \%)\end{array}$ & $\begin{array}{c}6 \\
(-63 \%)\end{array}$ & $\begin{array}{c}4 \\
(-75 \%)\end{array}$ \\
\hline $\mathrm{BE}$ & 6 & $\begin{array}{c}5 \\
(-17 \%)\end{array}$ & $\begin{array}{c}5 \\
(-17 \%)\end{array}$ & $\begin{array}{c}5 \\
(-17 \%)\end{array}$ & $\begin{array}{c}4 \\
(-33 \%)\end{array}$ & 9 & $\begin{array}{c}5 \\
(-44 \%)\end{array}$ & $\begin{array}{c}5 \\
(-44 \%)\end{array}$ & $\begin{array}{c}5 \\
(-44 \%)\end{array}$ & $\begin{array}{c}4 \\
(-56 \%)\end{array}$ \\
\hline FR & 8 & $\begin{array}{c}6 \\
(-25 \%)\end{array}$ & $\begin{array}{c}6 \\
(-25 \%)\end{array}$ & $\begin{array}{c}4 \\
(-50 \%)\end{array}$ & $\begin{array}{c}4 \\
(-50 \%)\end{array}$ & 13 & $\begin{array}{c}8 \\
(-38 \%)\end{array}$ & $\begin{array}{c}7 \\
(-46 \%)\end{array}$ & $\begin{array}{c}6 \\
(-54 \%)\end{array}$ & $\begin{array}{c}5 \\
(-62 \%)\end{array}$ \\
\hline $\mathrm{CH}$ & 4 & $\begin{array}{c}2 \\
(-50 \%)\end{array}$ & $\begin{array}{c}2 \\
(-50 \%)\end{array}$ & $\begin{array}{c}2 \\
(-50 \%)\end{array}$ & $\begin{array}{c}1 \\
(-75 \%)\end{array}$ & 9 & $\begin{array}{c}5 \\
(-44 \%)\end{array}$ & $\begin{array}{c}4 \\
(-56 \%)\end{array}$ & $\begin{array}{c}3 \\
(-67 \%)\end{array}$ & $\begin{array}{c}2 \\
(-78 \%)\end{array}$ \\
\hline AT & 8 & $\begin{array}{c}9 \\
(13 \%)\end{array}$ & $\begin{array}{c}7 \\
(-13 \%)\end{array}$ & $\begin{array}{c}7 \\
(-13 \%)\end{array}$ & $\begin{array}{c}7 \\
(-13 \%)\end{array}$ & 23 & $\begin{array}{c}15 \\
(-35 \%)\end{array}$ & $\begin{array}{c}11 \\
(-52 \%)\end{array}$ & $\begin{array}{c}10 \\
(-57 \%)\end{array}$ & $\begin{array}{c}5 \\
(-78 \%)\end{array}$ \\
\hline ES & 18 & $\begin{array}{c}9 \\
(-50 \%)\end{array}$ & $\begin{array}{c}6 \\
(-67 \%)\end{array}$ & $\begin{array}{c}7 \\
(-61 \%)\end{array}$ & $\begin{array}{c}7 \\
(-61 \%)\end{array}$ & 21 & $\begin{array}{c}11 \\
(-48 \%)\end{array}$ & $\begin{array}{c}11 \\
(-48 \%)\end{array}$ & $\begin{array}{c}8 \\
(-62 \%)\end{array}$ & $\begin{array}{c}6 \\
(-71 \%)\end{array}$ \\
\hline IT & 11 & $\begin{array}{c}7 \\
(-36 \%)\end{array}$ & $\begin{array}{c}8 \\
(-27 \%)\end{array}$ & $\begin{array}{c}6 \\
(-45 \%)\end{array}$ & $\begin{array}{c}6 \\
(-45 \%)\end{array}$ & 23 & $\begin{array}{c}12 \\
(-48 \%)\end{array}$ & $\begin{array}{c}11 \\
(-52 \%)\end{array}$ & $\begin{array}{c}10 \\
(-57 \%)\end{array}$ & $\begin{array}{c}9 \\
-61 \%)\end{array}$ \\
\hline $\mathrm{CZ}$ & 10 & $\begin{array}{c}8 \\
(-20 \%)\end{array}$ & $\begin{array}{c}7 \\
(-30 \%)\end{array}$ & $\begin{array}{c}6 \\
(-40 \%)\end{array}$ & $\begin{array}{c}4 \\
(-60 \%)\end{array}$ & 18 & $\begin{array}{c}15 \\
(-17 \%)\end{array}$ & $\begin{array}{c}11 \\
(-39 \%)\end{array}$ & $\begin{array}{c}9 \\
(-50 \%)\end{array}$ & $\begin{array}{c}7 \\
(-61 \%)\end{array}$ \\
\hline PL & 9 & $\begin{array}{c}6 \\
(-33 \%) \\
\end{array}$ & $\begin{array}{c}5 \\
(-44 \%) \\
\end{array}$ & $\begin{array}{c}4 \\
(-56 \%) \\
\end{array}$ & $\begin{array}{c}2 \\
(-78 \%) \\
\end{array}$ & 29 & $\begin{array}{c}12 \\
(-59 \%) \\
\end{array}$ & $\begin{array}{c}9 \\
(-69 \%) \\
\end{array}$ & $\begin{array}{c}7 \\
(-76 \%) \\
\end{array}$ & $\begin{array}{c}5 \\
(-83 \%) \\
\end{array}$ \\
\hline
\end{tabular}


Table 6. Fitted median and percentage variations from the first quintile (in parentheses) of the RSSW index by country of residence, quintile of ALTI and gender - retirees

\begin{tabular}{|c|c|c|c|c|c|c|c|c|c|c|}
\hline \multicolumn{6}{|c|}{ RETIREES - MEN } & \multicolumn{5}{|c|}{ RETIREES - WOMEN } \\
\hline Country & Q1 & $\mathrm{Q} 2$ & Q3 & Q4 & Q5 & Q1 & Q2 & Q3 & Q4 & Q5 \\
\hline \multirow[t]{2}{*}{ SE } & 14 & 6 & 4 & 3 & 2 & 15 & 8 & 6 & 5 & 3 \\
\hline & & $-57 \%$ & $-71 \%$ & $-79 \%$ & $-86 \%$ & & $-47 \%$ & $-60 \%$ & $-67 \%$ & $-80 \%$ \\
\hline \multirow[t]{2}{*}{ DK } & 6 & 3 & 2 & 1 & 1 & 14 & 7 & 5 & 3 & 2 \\
\hline & & $-50 \%$ & $-67 \%$ & $-83 \%$ & $-83 \%$ & & $-50 \%$ & $-64 \%$ & $-79 \%$ & $-86 \%$ \\
\hline \multirow[t]{2}{*}{$\mathrm{DE}$} & 13 & 7 & 6 & 5 & 4 & 9 & 8 & 6 & 6 & 4 \\
\hline & & $-46 \%$ & $-54 \%$ & $-62 \%$ & $-69 \%$ & & $-11 \%$ & $-33 \%$ & $-33 \%$ & $-56 \%$ \\
\hline \multirow[t]{2}{*}{ NL } & 15 & 6 & 4 & 3 & 2 & 30 & 16 & 11 & 8 & 4 \\
\hline & & $-60 \%$ & $-73 \%$ & $-80 \%$ & $-87 \%$ & & $-47 \%$ & $-63 \%$ & $-73 \%$ & $-87 \%$ \\
\hline \multirow[t]{2}{*}{$\mathrm{BE}$} & 18 & 12 & 8 & 6 & 4 & 19 & 13 & 13 & 10 & 5 \\
\hline & & $-33 \%$ & $-56 \%$ & $-67 \%$ & $-78 \%$ & & $-32 \%$ & $-32 \%$ & $-47 \%$ & $-74 \%$ \\
\hline \multirow[t]{2}{*}{ FR } & 22 & 11 & 7 & 5 & 2 & 31 & 12 & 10 & 7 & 2 \\
\hline & & $-50 \%$ & $-68 \%$ & $-77 \%$ & $-91 \%$ & & $-61 \%$ & $-68 \%$ & $-77 \%$ & $-94 \%$ \\
\hline \multirow[t]{2}{*}{$\mathrm{CH}$} & 5 & 4 & 3 & 2 & 2 & 11 & 7 & 5 & 4 & 3 \\
\hline & & $-20 \%$ & $-40 \%$ & $-60 \%$ & $-60 \%$ & & $-36 \%$ & $-55 \%$ & $-64 \%$ & $-73 \%$ \\
\hline \multirow[t]{2}{*}{ AT } & 39 & 18 & 13 & 8 & 5 & 32 & 15 & 14 & 10 & 6 \\
\hline & & $-54 \%$ & $-67 \%$ & $-79 \%$ & $-87 \%$ & & $-53 \%$ & $-56 \%$ & $-69 \%$ & $-81 \%$ \\
\hline \multirow[t]{2}{*}{ ES } & 93 & 22 & 11 & 6 & 3 & 77 & 34 & 19 & 7 & 3 \\
\hline & & $-76 \%$ & $-88 \%$ & $-94 \%$ & $-97 \%$ & & $-56 \%$ & $-75 \%$ & $-91 \%$ & $-96 \%$ \\
\hline \multirow[t]{2}{*}{ IT } & 28 & 12 & 11 & 6 & 4 & 79 & 14 & 13 & 6 & 3 \\
\hline & & $-57 \%$ & $-61 \%$ & $-79 \%$ & $-86 \%$ & & $-82 \%$ & $-84 \%$ & $-92 \%$ & $-96 \%$ \\
\hline \multirow[t]{2}{*}{$\mathrm{CZ}$} & 12 & 10 & 7 & 5 & 3 & 18 & 14 & 11 & 9 & 6 \\
\hline & & $-17 \%$ & $-42 \%$ & $-58 \%$ & $-75 \%$ & & $-22 \%$ & $-39 \%$ & $-50 \%$ & $-67 \%$ \\
\hline \multirow[t]{2}{*}{ PL } & 29 & 15 & 11 & 9 & 4 & 39 & 22 & 16 & 13 & 5 \\
\hline & & $-48 \%$ & $-62 \%$ & $-69 \%$ & $-86 \%$ & & $-44 \%$ & $-59 \%$ & $-67 \%$ & $-87 \%$ \\
\hline
\end{tabular}


Table 7. Quintiles of the household distributions of SSW, real assets and financial assets

\begin{tabular}{|c|c|c|c|c|c|c|c|c|c|c|c|c|c|c|c|}
\hline & \multicolumn{5}{|c|}{ Household SSW } & \multicolumn{5}{|c|}{ Household real assets } & \multicolumn{5}{|c|}{ Household financial assets } \\
\hline & Q1 & Q2 & Q3 & Q4 & Q5 & Q1 & Q2 & Q3 & Q4 & Q5 & Q1 & Q2 & Q3 & Q4 & Q5 \\
\hline$\overline{\text { SE }}$ & 106.7 & 149.7 & 210.5 & 269.0 & 368.0 & 0.0 & 64.4 & 123.4 & 220.4 & 528.9 & 1.8 & 19.0 & 43.1 & 92.1 & 197.4 \\
\hline DK & 59.1 & 74.7 & 112.3 & 126.9 & 153.8 & 0.0 & 61.6 & 118.1 & 193.6 & 395.9 & 0.2 & 12.3 & 35.3 & 79.8 & 200.8 \\
\hline DE & 36.0 & 117.3 & 182.1 & 242.4 & 354.1 & 0.0 & 36.2 & 108.6 & 199.2 & 380.2 & 0.0 & 5.4 & 18.1 & 42.1 & 135.8 \\
\hline NL & 92.7 & 116.7 & 152.8 & 179.3 & 207.0 & 0.0 & 64.0 & 148.3 & 228.5 & 420.4 & 0.5 & 8.0 & 22.8 & 48.8 & 141.9 \\
\hline BE & 103.2 & 167.8 & 220.1 & 324.8 & 1445.1 & 0.0 & 151.5 & 216.4 & 288.2 & 519.3 & 1.1 & 16.4 & 44.0 & 110.3 & 292.9 \\
\hline FR & 101.5 & 145.5 & 203.2 & 285.2 & 469.4 & 0.0 & 144.0 & 225.0 & 319.7 & 540.0 & 0.0 & 7.2 & 24.8 & 62.1 & 168.5 \\
\hline $\mathrm{CH}$ & 106.7 & 135.7 & 204.0 & 249.8 & 342.9 & 0.0 & 48.4 & 134.1 & 291.5 & 699.5 & 0.4 & 23.3 & 70.0 & 155.1 & 378.4 \\
\hline AT & 108.5 & 173.8 & 219.8 & 292.6 & 447.7 & 0.0 & 35.3 & 84.0 & 172.8 & 315.4 & 0.0 & 2.4 & 9.0 & 22.9 & 60.0 \\
\hline ES & 83.3 & 114.6 & 153.0 & 203.2 & 304.1 & 40.1 & 101.9 & 153.2 & 245.1 & 519.1 & 0.0 & 0.2 & 4.6 & 10.2 & 53.7 \\
\hline IT & 74.9 & 114.8 & 170.2 & 226.9 & 364.9 & 0.0 & 119.2 & 177.0 & 309.8 & 531.0 & 0.0 & 2.7 & 11.5 & 26.6 & 71.2 \\
\hline $\mathrm{CZ}$ & 75.7 & 116.1 & 150.0 & 198.2 & 262.4 & 0.0 & 54.0 & 101.3 & 155.4 & 270.2 & 0.0 & 2.0 & 6.3 & 14.3 & 36.1 \\
\hline PL & 44.3 & 69.4 & 98.1 & 140.1 & 191.5 & 0.0 & 21.8 & 43.6 & 72.7 & 143.2 & 3.6 & & 3.8 & 5.4 & 10.9 \\
\hline
\end{tabular}

Note: Amounts are PPP-adjusted and expressed in thousands of 2010 euros. 
Figure 1. Distributions of social security wealth, by employment status and gender

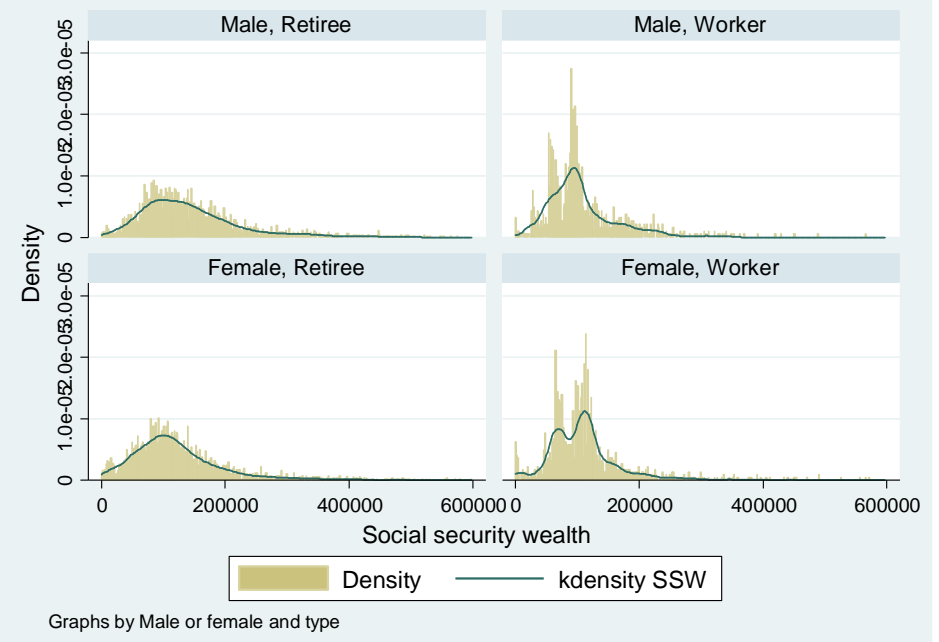

Note: "kdensity" = Kernel density. 
Figure 2a. Box plot of SSW - Male workers

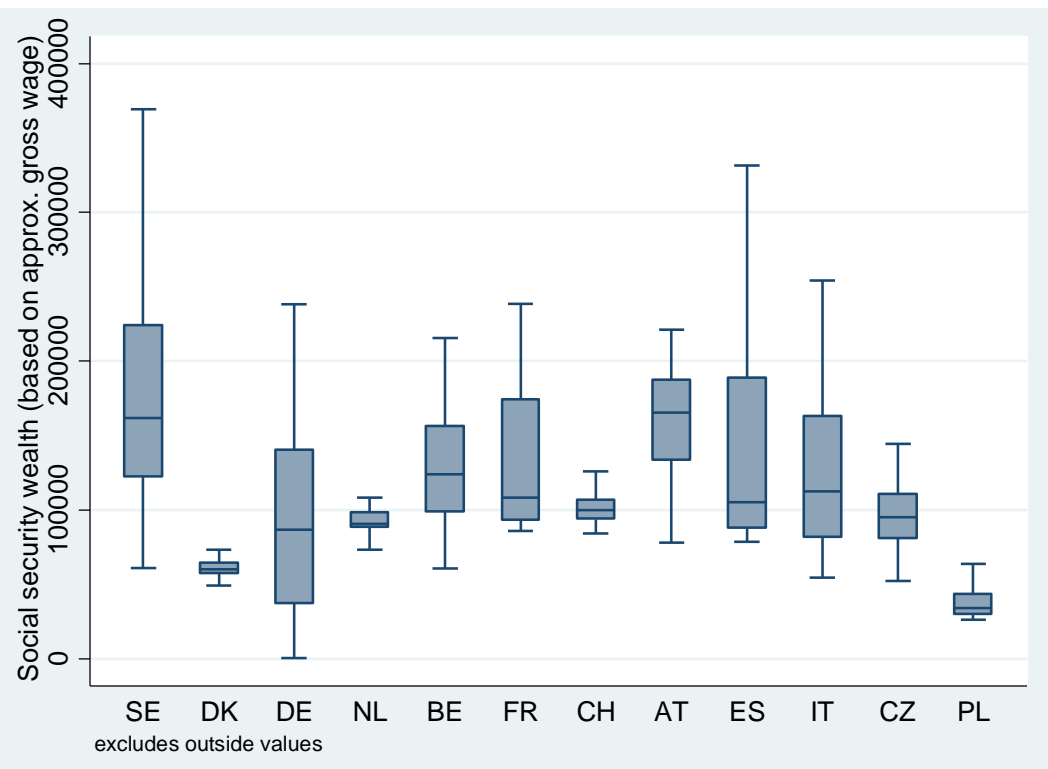

Figure 2b. Box plot of SSW - Female workers

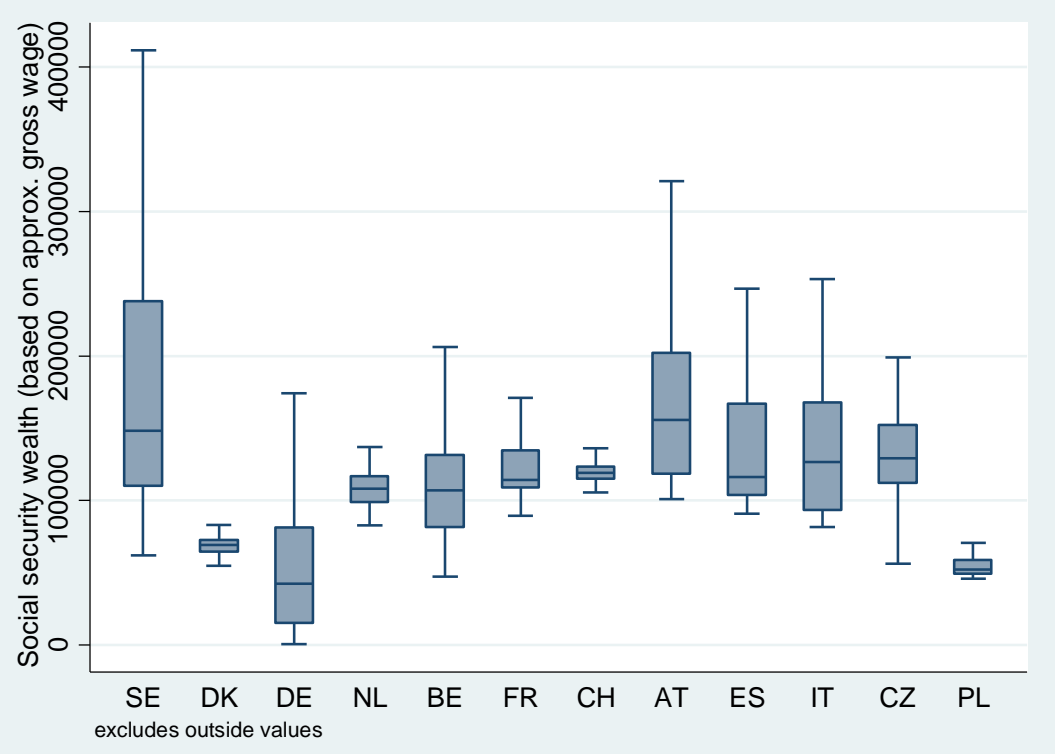


Figure 2c. Box plot of SSW - Male retirees

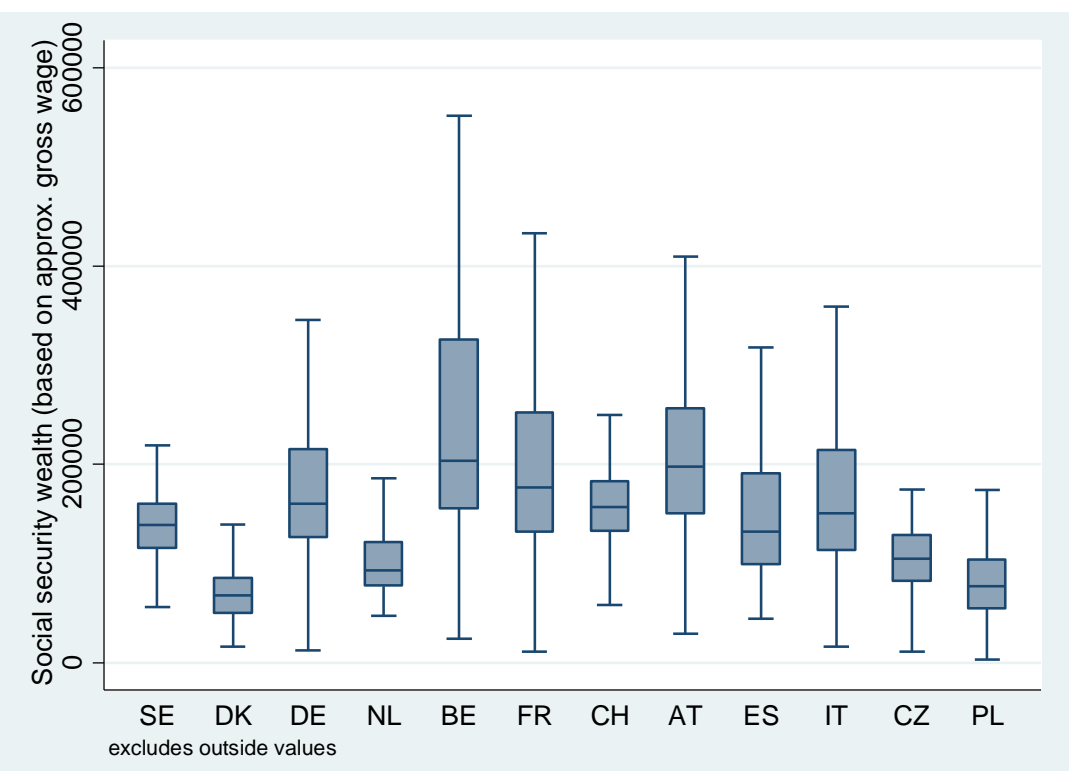

Figure 2d. Box plot of SSW - Female retirees

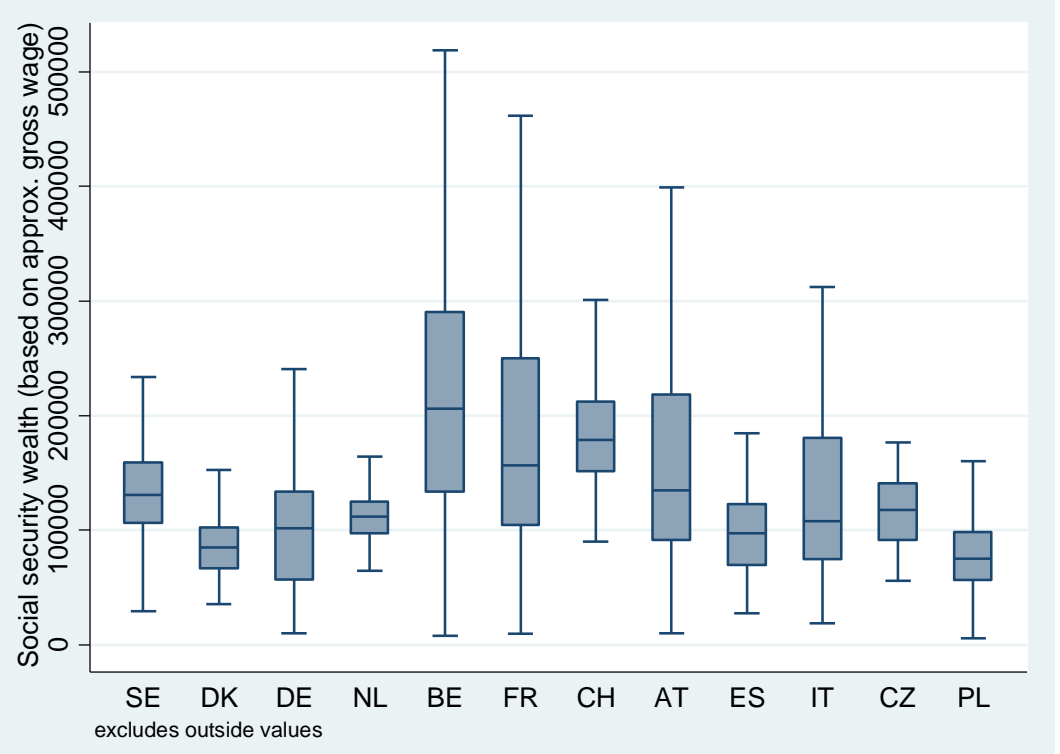


Figure 3. Distributions of Average LifeTime Income (ALTI), by employment status and gender

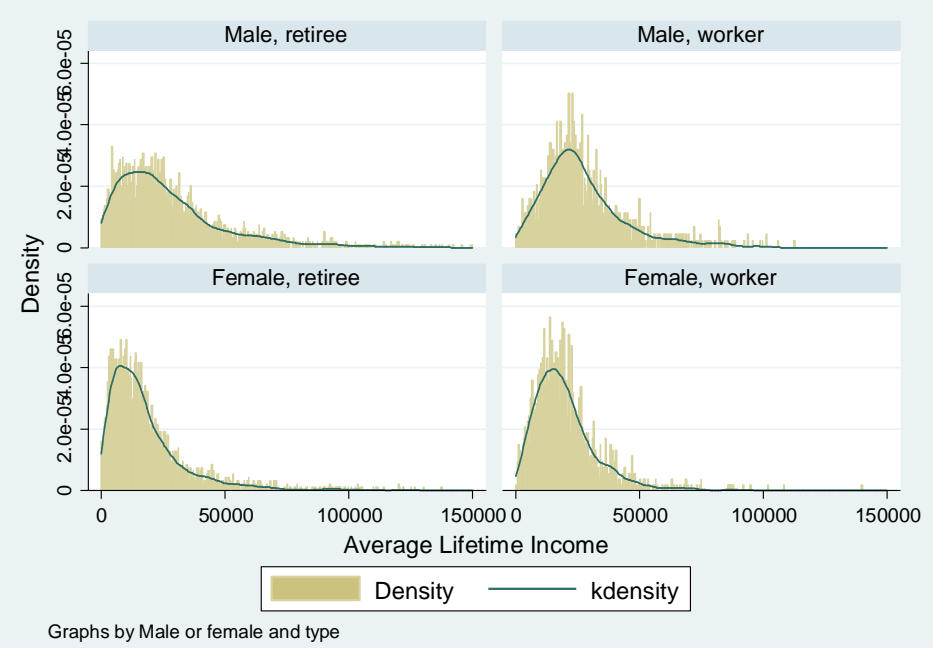

Note: "kdensity" = Kernel density.

Figure 4. Fitted median and $95 \%$ confidence interval of the RSSW index for workers by quintile of ALTI and gender: Germany

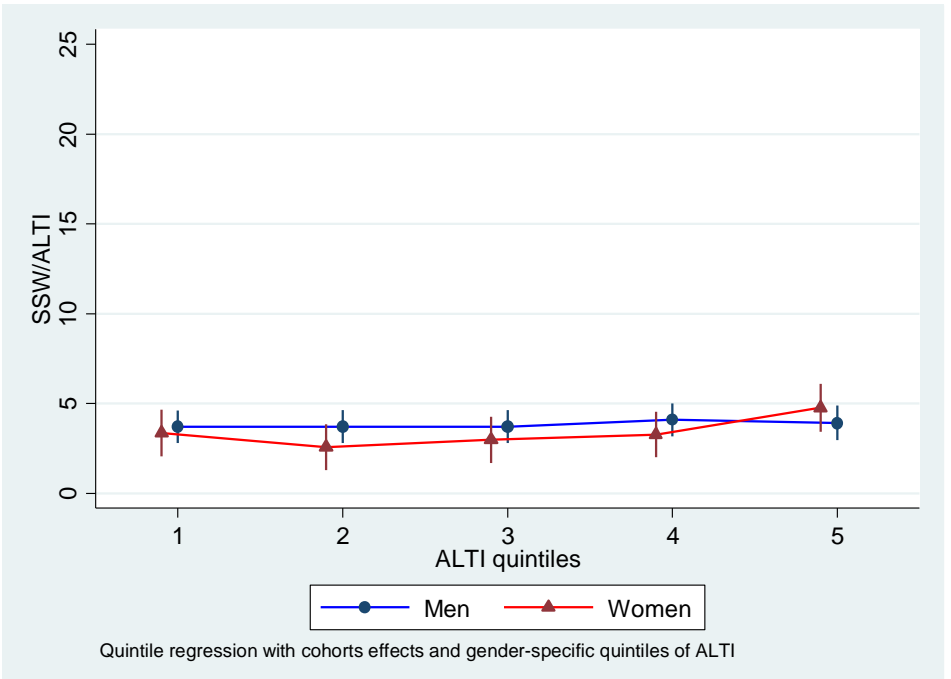


Figure 5. Fitted median and $95 \%$ confidence interval of the RSSW index for workers by quintile of ALTI and gender: Spain (upper panel) and Italy (lower panel)
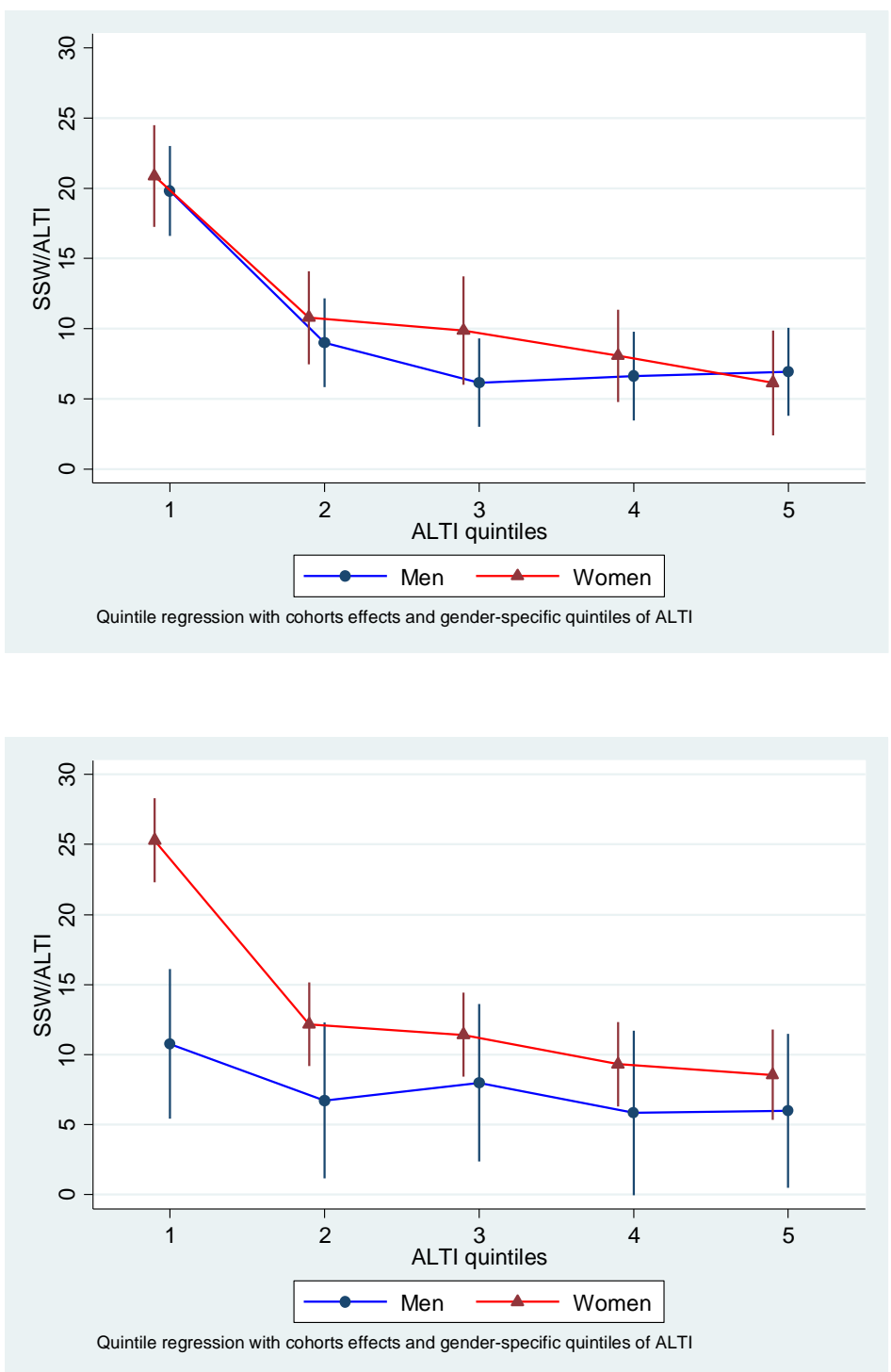
Figure 6. Fitted median and $95 \%$ confidence interval of the RSSW index for workers by quintile of ALTI and gender: Denmark (upper panel) and The Netherlands (lower panel)
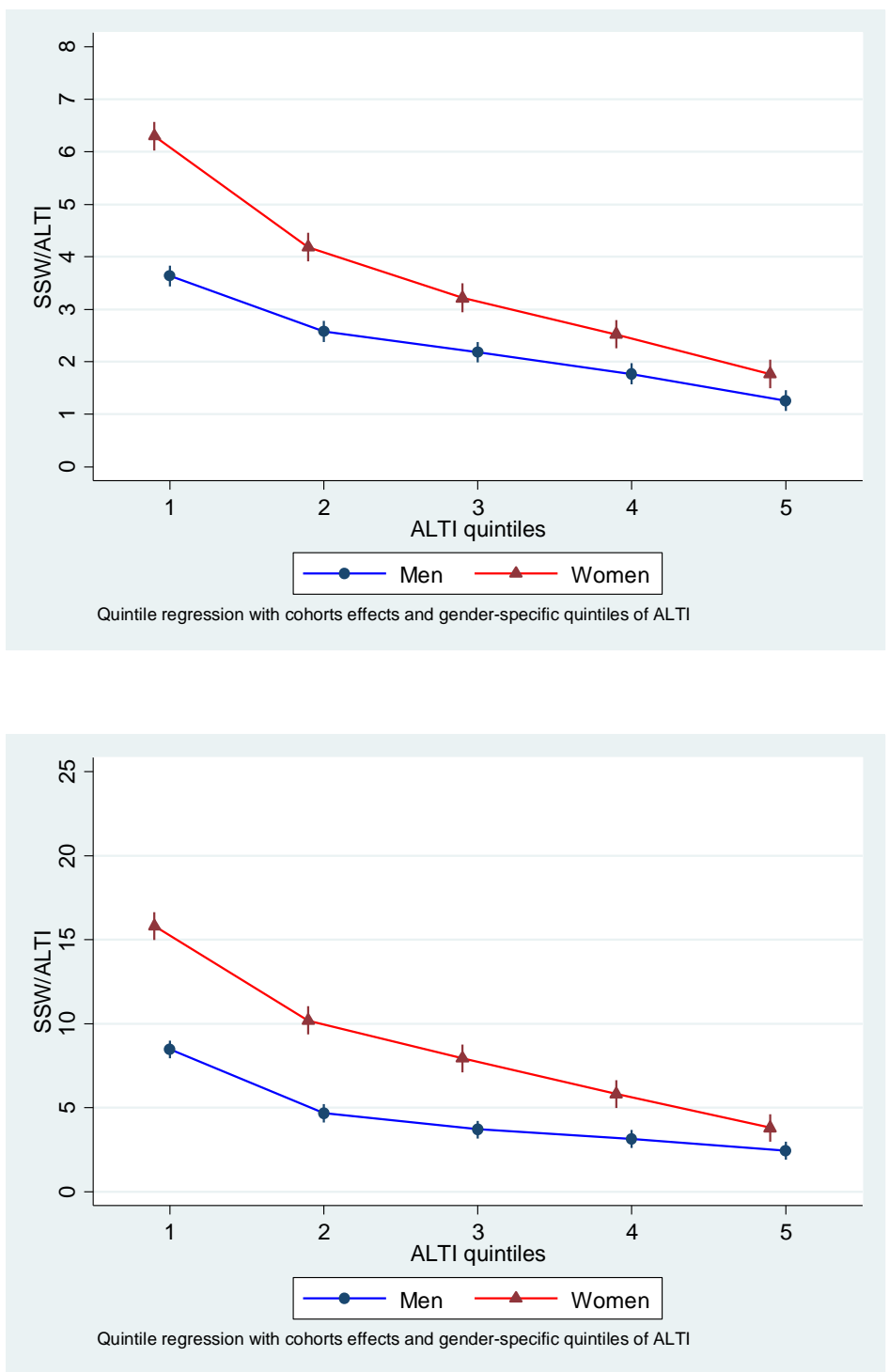
Figure 7. Fitted median and $95 \%$ confidence interval of the RSSW index by quintile of ALTI and gender for Germany: retirees

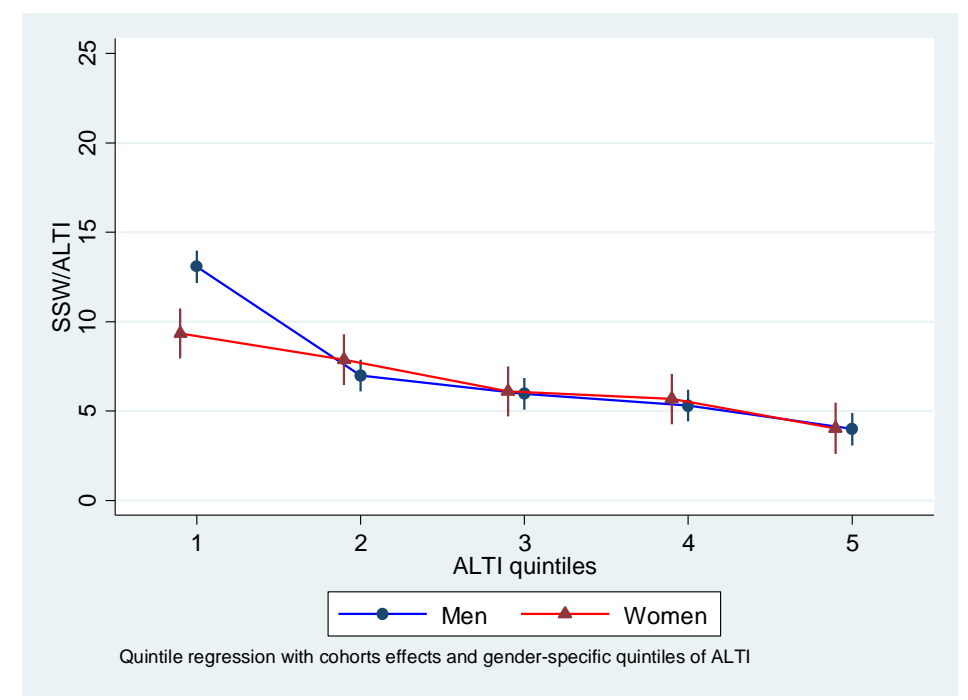

Figure 8. Share of social security wealth versus share of financial wealth, by country

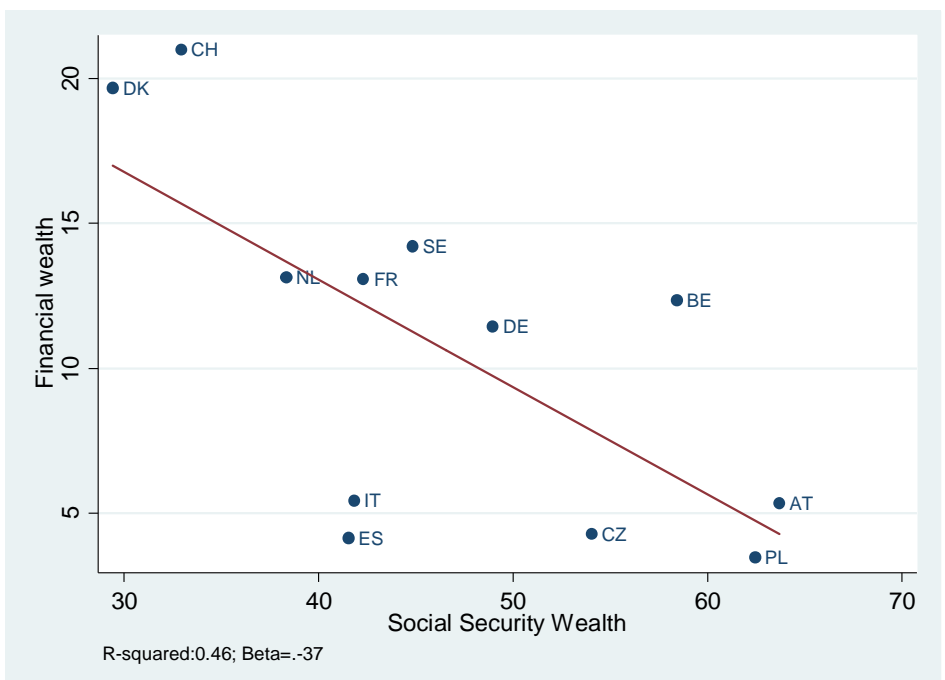


Figure 9. Share of social security wealth versus share of net real wealth, by country

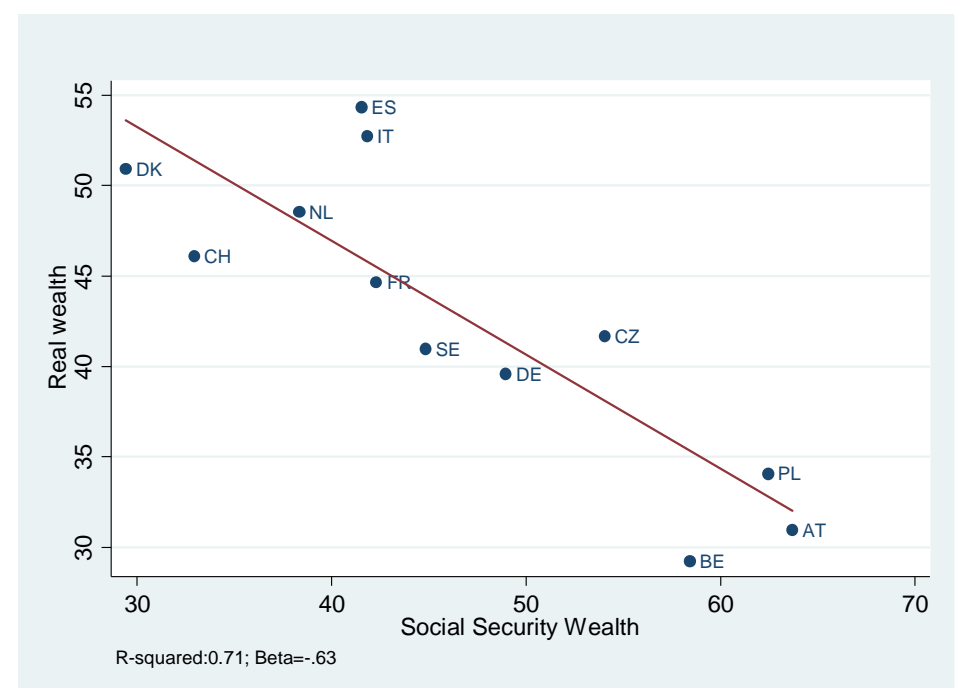

Figure 10. Share of social security wealth versus share of financial wealth European macro regions (NUTS1)

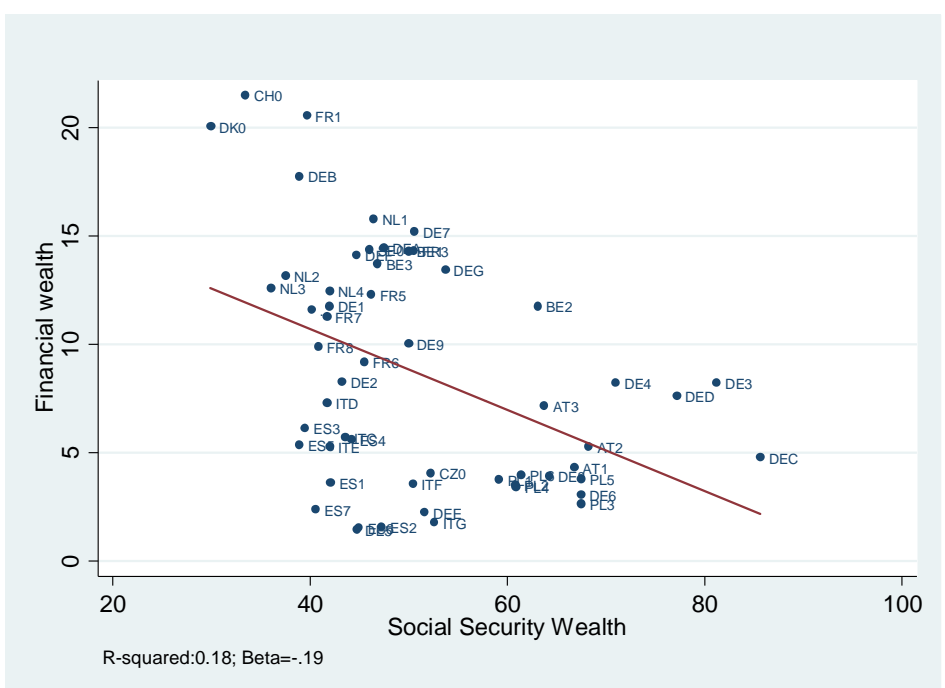


Figure 11. Share of social security wealth versus share of net real wealth European macro regions (NUTS1)

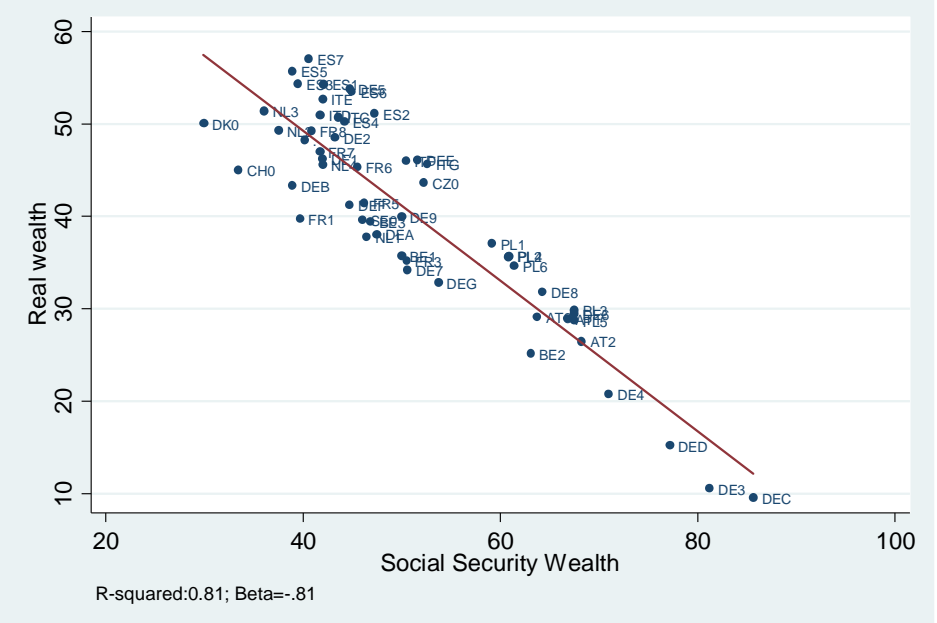




\section{Appendix}

Table A.1. Gini coefficients of SSW and of Lifetime Income (LTI) and the progressivity index, by country

\begin{tabular}{|c|c|c|c|c|c|c|c|c|c|c|c|c|}
\hline \multicolumn{5}{|c|}{ Gini_SSW } & \multicolumn{4}{|c|}{ Gini_LTI } & \multicolumn{4}{|c|}{ Progressivity Index } \\
\hline & \multicolumn{2}{|c|}{ Workers } & \multicolumn{2}{|c|}{ Retirees } & \multicolumn{2}{|c|}{ Workers } & \multicolumn{2}{|c|}{ Retirees } & \multicolumn{2}{|c|}{ Workers } & \multicolumn{2}{|c|}{ Retirees } \\
\hline & Men & Women & Men & Women & Men & Women & Men & Women & Men & Women & Men & Women \\
\hline SE & 0.30 & 0.32 & 0.19 & 0.29 & 0.46 & 0.52 & 0.51 & 0.57 & 34.78 & 38.46 & 62.75 & 49.12 \\
\hline DK & 0.05 & 0.05 & 0.21 & 0.18 & 0.45 & 0.56 & 0.47 & 0.6 & 88.89 & 91.07 & 55.32 & 70.00 \\
\hline $\mathrm{DE}$ & 0.41 & 0.48 & 0.26 & 0.34 & 0.33 & 0.38 & 0.33 & 0.42 & -24.24 & -26.32 & 21.21 & 19.05 \\
\hline NL & 0.08 & 0.09 & 0.19 & 0.12 & 0.35 & 0.54 & 0.42 & 0.63 & 77.14 & 83.33 & 54.76 & 80.95 \\
\hline $\mathrm{BE}$ & 0.16 & 0.19 & 0.6 & 0.59 & 0.37 & 0.43 & 0.42 & 0.44 & 56.76 & 55.81 & -42.86 & -34.09 \\
\hline FR & 0.19 & 0.14 & 0.27 & 0.36 & 0.42 & 0.51 & 0.79 & 0.82 & 54.76 & 72.55 & 65.82 & 56.10 \\
\hline $\mathrm{CH}$ & 0.05 & 0.04 & 0.21 & 0.25 & 0.3 & 0.45 & 0.28 & 0.47 & 83.33 & 91.11 & 25.00 & 46.81 \\
\hline $\mathrm{AT}$ & 0.18 & 0.22 & 0.31 & 0.39 & 0.35 & 0.43 & 0.47 & 0.51 & 48.57 & 48.84 & 34.04 & 23.53 \\
\hline ES & 0.26 & 0.2 & 0.27 & 0.28 & 0.53 & 0.58 & 0.7 & 0.68 & 50.94 & 65.52 & 61.43 & 58.82 \\
\hline IT & 0.24 & 0.21 & 0.26 & 0.35 & 0.37 & 0.4 & 0.61 & 0.71 & 35.14 & 47.50 & 57.38 & 50.70 \\
\hline $\mathrm{CZ}$ & 0.14 & 0.15 & 0.22 & 0.2 & 0.63 & 0.57 & 0.5 & 0.37 & 77.78 & 73.68 & 56.00 & 45.95 \\
\hline PL & 0.20 & 0.11 & 0.25 & 0.24 & 0.86 & 0.54 & 0.94 & 0.95 & 76.74 & 79.63 & 73.40 & 74.74 \\
\hline
\end{tabular}

Figure A.1. Distributions of LifeTime Income (LTI), by employment status and gender

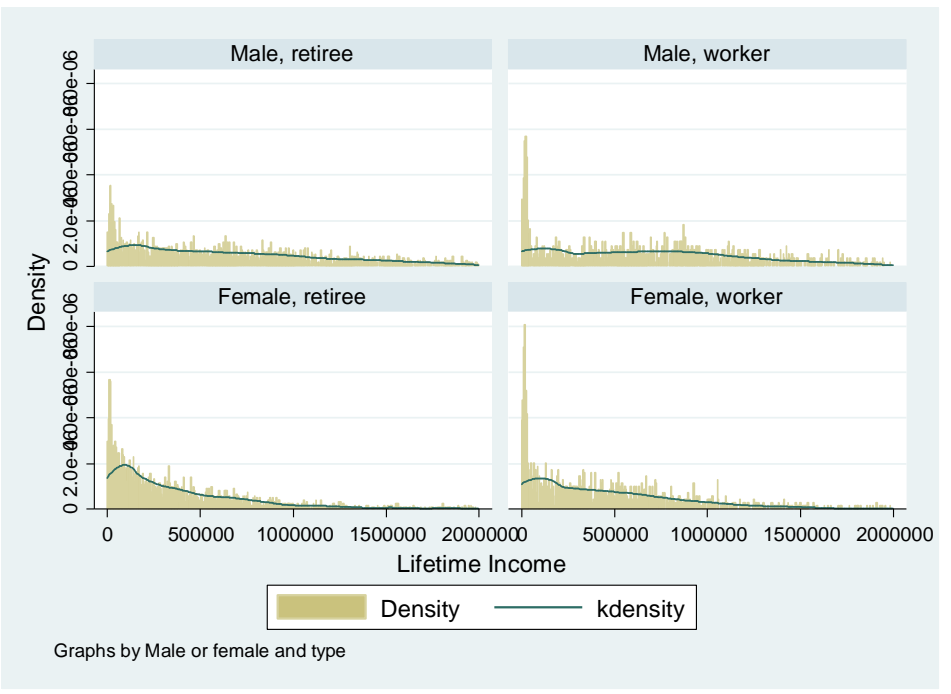

Note: "kdensity" = Kernel density . 